Historic, Archive Document

Do not assume content reflects current scientific knowledge, policies, or practices. 


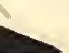


1999.9

$=76320$

$\rightarrow$ United States

Department of

Agriculture

Forest Service

Rocky Mountain

Forest and Range

Experiment Station

Fort Collins,

Colorado 80526

Research Paper

RM-295

Uis

\section{A Microplot Method for Updating Loop Frequency Range Trend Data: Theoretical Considerations and a Computer Simulation}

Ward W. Brady, John W. Cook, and Earl F. Aldon

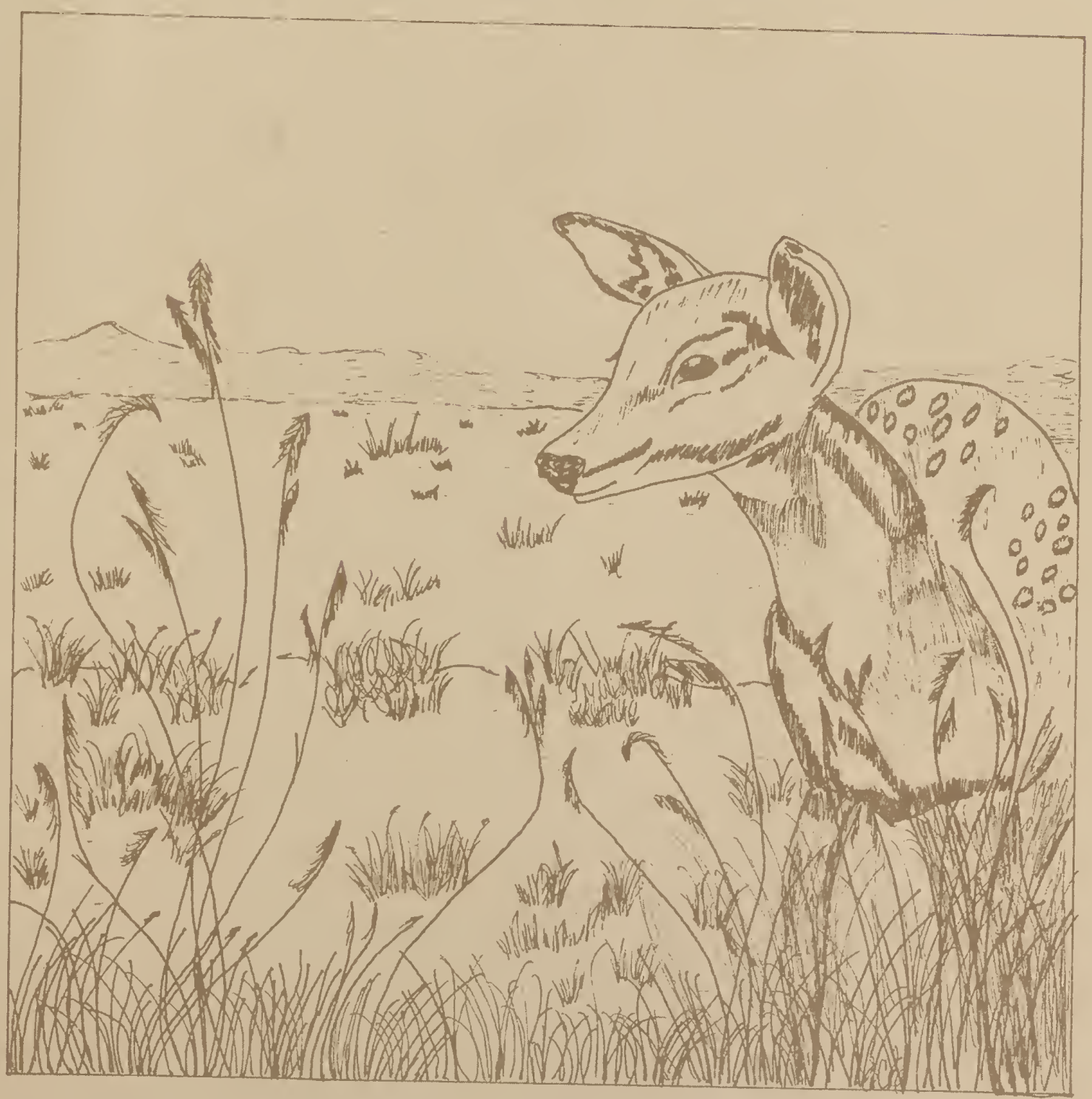




\title{
A Microplot Method for Updating Loop Frequency Range Trend Data: Theoretical Considerations and a Computer Simulation
}

\author{
Ward W. Brady, Professor \\ Arizona State University \\ John W. Cook, Research Associate \\ Arizona State University \\ Earl F. Aldon, Research Forester \\ Rocky Mountain Forest and Range Experiment Station'
}

\begin{abstract}
Quantitative forms of the relationships between 3/4-inch loop frequency data (Parker 3-step) and data from the Community Structure Analysis (CSA) sampling method were determined from computer simulations of grassland vegetation populations. Percent basal area (measured using the CSA microplot) had a stronger and simpler relationship with Parker frequency than did CSA canopy cover, CSA density, or CSA frequency. Data from three or more 100 -foot transects from homogeneous locations had significantly higher precision than data collected from single transects. A table for converting Parker data to percent basal area was developed for plants with mean basal diameters between 0.3 and $33.6 \mathrm{~cm}$. Conversion of old Parker data to basal area should provide a basis for ecological interpretation of long-term changes in range vegetation.
\end{abstract}

\section{USDA. National Agricultural Library \\ NAL Building \\ 10301 Baltimore Blud. \\ Beltsville, MO 20705.2351}

${ }^{1}$ Headquarters is in Fort Collins, in cooperation with Colorado State University. 


\title{
A Microplot Method for Updating Loop Frequency Range Trend Data: Theoretical Considerations and a Computer Simulation
}

\author{
Ward W. Brady, John W. Cook, and Earl F. Aldon
}

\section{Management Implications}

Although Parker 3-step data have been collected on western rangelands since the early 1950's, much of these data remained underutilized because of difficulties in interpretation. The existence of a relationship between 3/4-inch loop frequency and basal area allows historical Parker 3-step data to be interpreted in terms of this more ecologically meaningful parameter. Interpreting old Parker frequency records in terms of basal area assumes that mean plant basal diameter can be estimated and that plant populations are neither completely randomly nor very highly contagiously distributed. Evaluation of subjective information from old Parker records is necessary to determine if these assumptions can be met.

Tables for converting Parker data to percent basal area were developed for plants with mean basal diameters between 0.3 and $33.6 \mathrm{~cm}$. While future sampling with the Parker 3-step method is not recommended, conversion of old Parker data to basal area provides a basis for ecological interpretation of long-term changes in range vegetation.

\section{Introduction}

Parker 3-step clusters have been established on national forests throughout the western United States (Parker 1951, Parker and Harris 1959, Reppert and Francis 1973). For many locations these clusters provide the longest historical record of apparent vegetation change. Unfortunately, data collected from these clusters, often dating to the 1950's, have been underutilized because of difficulty in obtaining an ecological interpretation of Parker "hits." Other sampling designs, such as the Community Structure Analysis (CSA) method (Morris 1973, Pase 1981), provide repeatable, interpretable, and statistically reliable data on better defined vegetation parameters (particularly cover and density), which are more useful for ecological interpretation and in management applications.

If a relationship could be established between data collected using the Parker procedure and that collected using the CSA or a similar procedure, then a potentially powerful tool would exist that would aid in interpretation of the abundance of Parker data. By inputting Parker "hits" and predicting values for better understood vegetation parameters (e.g., cover, basal area, or density), the land manager would have a better tool for interpreting vegetation changes that have occurred during the last several decades.

\section{Background}

Basal frequency data (Daubenmire 1968), the probability of encountering the basal portion of a plant species in a plot frame, are easy to collect and are relatively free of observer error. The Parker 3-step sampling method is characterized by a number of procedurally advantageous attributes. A combination of small plot size (a 3/4-inch loop), clustered 100-foot transects on homogeneous sites, sampling times correlated with the phenological stage of vegetation, and simple data forms minimize observer and transcription error (Parker and Harris 1959, Sharp 1954). Johnston (1957) reported the Parker method to be more rapid than either line intercept or vertical point frame methods.

While frequency data are easy to collect, frequency is also dependent on plot size. Density of a species is directly related to frequency measurement only when the population exhibits a random distribution (Greig-Smith 1983). Few species, however, are randomly distributed, and because of dependence on plot size, frequency of a species is as much a function of sampling design as vegetation characteristics. This "artificial" nature of frequency data often makes it difficult to interpret results in relation to rangeland condition and trend (Aberdeen 1958, Greig-Smith 1983, West 1985).

Johnston (1957), Parker and Harris (1959), Kinsinger et al. (1960), and Francis et al. (1972) explored whether relationships existed between 3/4-inch loop frequency and more ecologically dependent sampling methods. Unfortunately, small sample sizes and observation errors hindered empirical analysis (Smith 1962). Additionally, a method was often defined as "best" because it provided the least variability among observations (precision) without knowing which method best approximated the true population mean (accuracy). Other attempts at determining accuracy of sampling and relationships between 3/4-inch loop data and other vegetation parameters were limited to theoretical analyses, which are themselves in need of empirical verification (Hutchings and Holmgren 1959).

Parker (1950) compared 3/4-inch loop frequency data, point frame sampling, paced transect data, and percent basal area as measured by the line intercept method. He concluded that 3/4-inch loop frequency data often shared a close relationship with the other data types. 
Hutchings and Holmgren (1959), using a theoretical model, found that mean plant basal diameter and plant numbers both influenced the relationship between Parker data and percent basal area. They suggested that plant shape and plant distribution may also have an effect. Species with basal diameters greater than a Parker plot showed a linear relationship between Parker frequency and percent basal area. As mean plant diameters increased above 2.5 inches $(6.35 \mathrm{~cm})$, Parker frequency readings more closely approximated the calculated percent basal areas. Species with mean basal diameters smaller than that of a Parker plot showed increasingly curvilinear relationships between Parker frequency and calculated percent basal areas. The authors found no consistent estimates of percent basal area by Parker frequency data in an empirical study that compared Parker sampling with percent basal area measured from populations of paper disks. Changes in plant size, numbers of plants per unit area, and percent basal area were derived from a series of pantographic maps that were sampled with Parker loop transects scaled to size. Results revealed misleading information from Parker data where interactions occurred between plant size and plant numbers.

Francis et al. (1972) compared 3/4-inch loop frequency against percent basal area as measured from line intercept and 3-point vertical frame sampling methods, percent canopy cover as measured from 4 - by 8-inch plot estimates, production estimates, and density from a 1by 20 -foot plot. They reported no consistent correlations between frequency and any of the other sampling methods and recommended against using Parker frequency data as an index to plant community characteristics.

Kinsinger et al. (1960) compared Parker frequency, line intercept data, and data from a variable plot method against actual measurements of canopy cover from 20by 25 - or 25 - by 50 -foot plots. They reported no significant differences among methods when calculated canopy covers were less than $5 \%$, but differences increased significantly as canopy cover increased, with Parker frequency increasingly overestimating "true" cover more than either of the other two methods.

Johnston (1957) compared Parker frequency and percent basal area estimates from line intercept and vertical point quadrat methods. Transects were subdivided such that each data point represented the mean of only a 10-foot segment. He reported some of the highest coefficients of variation for Parker data when measuring "dominant" species (percent basal area greater than $1 \%)$. While the Parker protocol was one of the most rapid sampling methods once the transect tape was in place, it detected the least number of species, overestimated percent basal area the most, and required the greatest number of 10 -foot transect clusters to meet the desired precision.

Smith (1962) compared Parker frequency data swith calculated basal areas of measured plants (using the formula for the area of a circle). He reported both plant size and plant density affected the relationship between Parker frequency and percent basal area. His results re- flected the inability of Parker plots to detect very small plants $(0.34 \mathrm{~cm})$. He considered the number of transects required for a given level of precision to be high and dependent upon plant size.

Brady (1988) analyzed Parker and CSA data collected on the Bernalillo Watershed Research Natural Area near Albuquerque, New Mexico. The Bernalillo Watershed has been protected from grazing since 1955. Parker data were available for the years 1955, 1961, 1965, 1970, 1975, 1980, and 1982 through 1987. CSA data were available only for the last seven of those years: 1980 and 1982-1987. On each Parker transect one hundred 5- by 10-cm CSA microplots were exactly centered over the one hundred 3/4-inch diameter Parker loops. Sampling was conducted on permanently located transects, and Parker loops were centered 1 foot apart. CSA canopy cover data were collected using the microplots, and Parker frequency was collected using the 3/4-inch loops. Ten $0.5-\mathrm{m}^{2}$ circular plots were used for CSA density and CSA frequency determinations; these were centered over every tenth Parker plot. Errors in species identification occurred over the 7 years of data collection and introduced substantial variation into the data set, particularly for species with similar physiognomy, such as the Bouteloua genus. In addition, small sample sizes $(10 \leq n \leq 48)$ made interpretation of data difficult. Several species (including most nongrass species) did not occur frequently enough to allow relationships between data types to be confidently estimated.

Parker "hits" from a transect (the independent variable) were plotted against percent CSA canopy cover, CSA density, and CSA frequency (the dependent variables) on the same transect for each species. Simple linear regression was used to determine relationships between data types. Results indicated that for several species Parker data were significantly related with CSA canopy cover and CSA density. Strength of these relationships varied over a wide range, at least in part, because of small sample sizes and species identification errors. However, available data did suggest that relationships could be described that would allow managers to equate data from Parker 3-step clusters to more ecologically sound and statistically reliable sampling techniques.

\section{Methods}

Computer simulations were used to determine relationships between data collected using 3/4-inch $(1.905-\mathrm{cm})$ diameter loops and both $5-$ by $10-\mathrm{cm}$ microplots and $0.5-\mathrm{m}^{2}$ plots. Use of simulations eliminated observation error and permitted sample sizes large enough to identify quantitative relationships. Computer simulations provided artificial vegetation maps with prescribed characteristics on the computer screen (fig. 1). Only one species was drawn on the screen for any given simulation. Vegetation parameters that could be modified included: mean plant diameter, variation in plant diameter, density or percent cover of plants, plant distribution (random to highly contagious), plant shape, 
and plant growth form (i.e., the ratio between canopy size and basal area). Shrubby species were not included in the simulation.

Sampling units of appropriate size and shape (as specified by the Parker and CSA protocols) were used to sample these artificial vegetation populations. The sampling units could be visually superimposed on the simulated population for illustration purposes (fig. 1).

All maps were drawn using graphics with a screen resolution of 640 by 480 pixels. Under this graphics mode, each pixel had equal height and width. For any given simulation, each pixel on the screen could be assigned an equivalent area, and both individual plants and sampling plots could be "drawn" on the screen with dimensions that were scaled to those found in the field. Several different scales were used in simulation. For example, in one simulation model each pixel on the computer screen was defined to be equivalent to an area of $0.077 \mathrm{~cm}^{2}$. A circle drawn on the screen with a radius of 3 pixels contained 37 pixels and had an equivalent area of $2.850-\mathrm{cm}^{2}$ or the area of a $3 / 4$-inch-diameter Parker plot. A CSA microplot ( 5 by $10 \mathrm{~cm}$ ) was assigned dimensions of 18 by 36 pixels plus 1 pixel or an equivalent area of $49.995 \mathrm{~cm}^{2}$. The $0.5-\mathrm{m}^{2}$ plot used in CSA density and frequency samples contained the number of pixels required for the area according to scale.

Sampling plots were located on the screen with interplot distances equivalent to that of a field sample. For example, a Parker loop had a diameter of 7 pixels along the horizontal plane of the screen. Placing the center of Parker loops 112 pixels apart gave spacings of an equivalent distance of 1 foot. Because of the spacing between sampling units on the screen, a sample of the equivalent of a 100 -foot transect required that the samples be spread over several independently generated vegetation maps (screens) with identical parameters. For each simulation a sample size of either 100 plots (1 Parker transect), 300 plots ( 3 Parker transects), or 600 plots (6 Parker transects) was chosen. Microplots centered over each Parker loop were used to collect canopy cover and basal area data. Density and CSA frequency data were col-

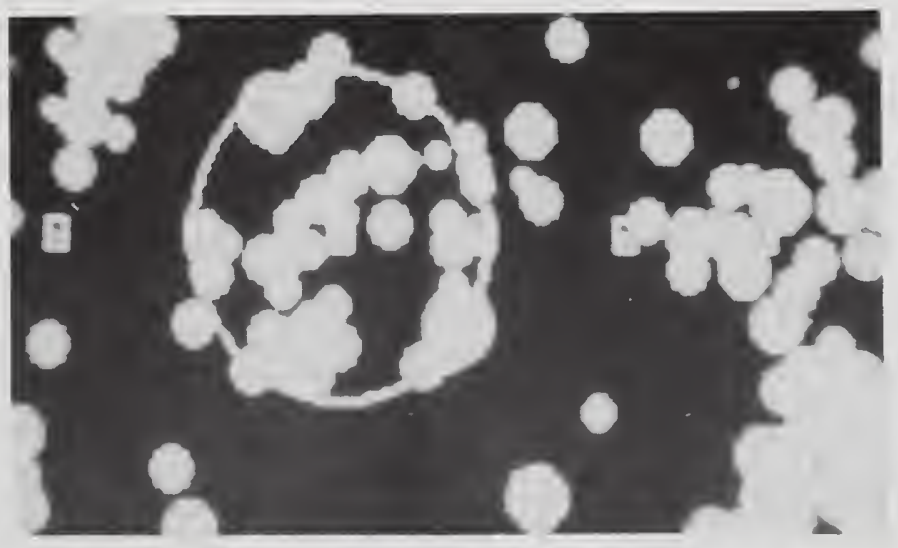

Figure 1.-Photograph of computer simulation of a vegetation community and the relatlve size, shape, and spacing of sampling plots. Rectangles located across the center of the photograph are 5 by $10-\mathrm{cm}$ microplots, $3 / 4-$ Inch Parker loops are located in the center of each rectangle, and the large clrcle near the center of the photograph is a $0.5-\mathrm{m}^{2}$ density plot. lected from $0.5-\mathrm{m}^{2}$ circular plots centered over every tenth Parker loop. Each transect, therefore, had one hundred 3/4-inch loops for Parker frequency, one hundred 5- by 10-cm microplots for basal area and CSA canopy cover, and ten $0.5-\mathrm{m}^{2}$ circular plots for CSA density and CSA frequency.

For each simulation, basal area was systematically varied between a specified upper and lower bound by a specified interval. Each increment between the upper and lower bounds was considered a cycle of the simulation. For example, if the maximum percent basal area for a simulation was set to 5.0 , the minimum at 0.1 and the interval at 0.1 , the first vegetation maps drawn would have approximately $5 \%$ basal area and subsequent maps would have the basal area reduced by $0.1 \%$ each cycle of the simulation until basal area was reduced to $0.1 \%$. When the minimum basal area was reached, then basal area was reset to the maximum and the procedure repeated until the required number of replications had been collected. Recorded vegetation parameters included Parker frequency, CSA canopy cover, CSA density, CSA frequency, and basal cover measured with the CSA microplot. CSA cover, basal cover, and CSA density measurements were evaluated for accuracy by comparing sample results against known screen parameters. Each simulation was continued until approximately 300 data points (each having either 100, 300, or 600 plots) had been collected. For a simulated sample of this size, a $16-\mathrm{Mhz} 80386$ based microcomputer required 6 to 10 hours of run-time.

The effect of various plant characteristics on relationships between Parker data and other CSA parameters was determined by holding all vegetation characteristics except one constant and then systematically varying the characteristic of interest. The effect of plant size, for example, was determined by holding plant distribution and other parameters constant while systematically changing plant size.

Prediction equations relating Parker and other data were determined using least squares regression procedures (Neter et al. 1985, Statgraphics 1989). A preliminary evaluation of these prediction equations was conducted using standard sampling equipment and artificial populations composed of paper disks. To evaluate adequacy of predicted basal area for management purposes, the procedure of Freese (1960) was used.

\section{Results and Discussion}

\section{CSA Density and Parker Frequency Relationships}

The relationship between CSA density and Parker frequency was dependent on mean plant basal diameter (fig. 2). As mean basal diameter increased, the number of Parker hits observed at any given density also increased. For example, at a density of 20 plants per square meter approximately 4 Parker hits would be observed for plants having a basal diameter of 3-cm, approximately 8 Parker hits for 6-cm plants and approximately 24 hits for 12-cm plants. 


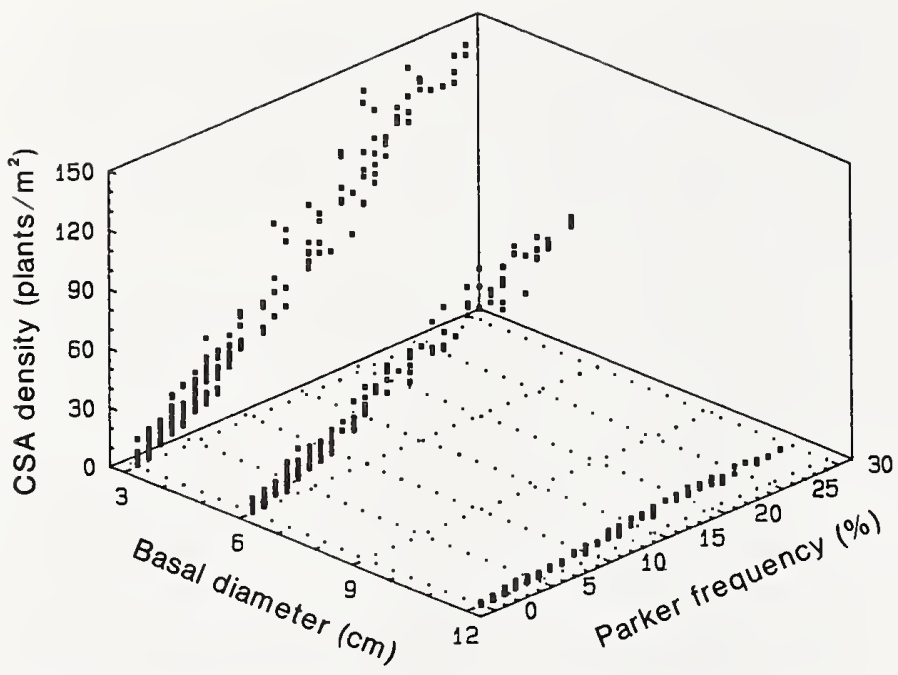

Figure 2.-Effect of basal diameter on the relationship between CSA density and Parker frequency for plants with basal diameters of 3,6 , and $12 \mathrm{~cm}$.

Larger diameter plants resulted in prediction equations with flatter slopes when CSA density (the dependent variable) was regressed against Parker frequency (the independent variable). Equations designed for prediction of CSA density must include both Parker frequency and a measure of mean plant basal size as independent variables. Regression equations fit to CSA density and Parker frequency data were statistically significant, with $R^{2}$ ranging from $75.1 \%$ to $88.5 \%$. Density observations, however, were from $0.5-\mathrm{m}^{2}$ circular plots centered over every tenth Parker loop, while other observations were from microplots centered over each Parker loop. The close association of Parker loops with CSA microplots generally resulted in less variable data than was observed with the fewer but larger CSA density plots.

\section{CSA Cover and Parker Frequency Relationships}

The relationship between CSA canopy cover and Parker frequency was dependent on the ratio between canopy and basal diameters of the plant species drawn on the screen (fig. 3). For any given canopy cover, a sample of plants having a larger canopy/basal diameter ratio (i.e., equal percent canopy area but smaller percent basal area in the community) resulted in fewer Parker hits than a sample of plants having a smaller canopy/basal diameter ratio. Plants with larger bases relative to size of the canopy had flatter slopes when CSA canopy cover (dependent variable) was regressed against Parker frequency (independent variable). Description of the relationship between CSA canopy cover and Parker frequency required that both Parker frequency and canopy/basal diameter ratio be included as independent variables. Similar to CSA density, regression equations fit to CSA canopy cover and Parker frequency data were statistically significant, with $R^{2}$ ranging from $56.3 \%$ to $96.5 \%$.

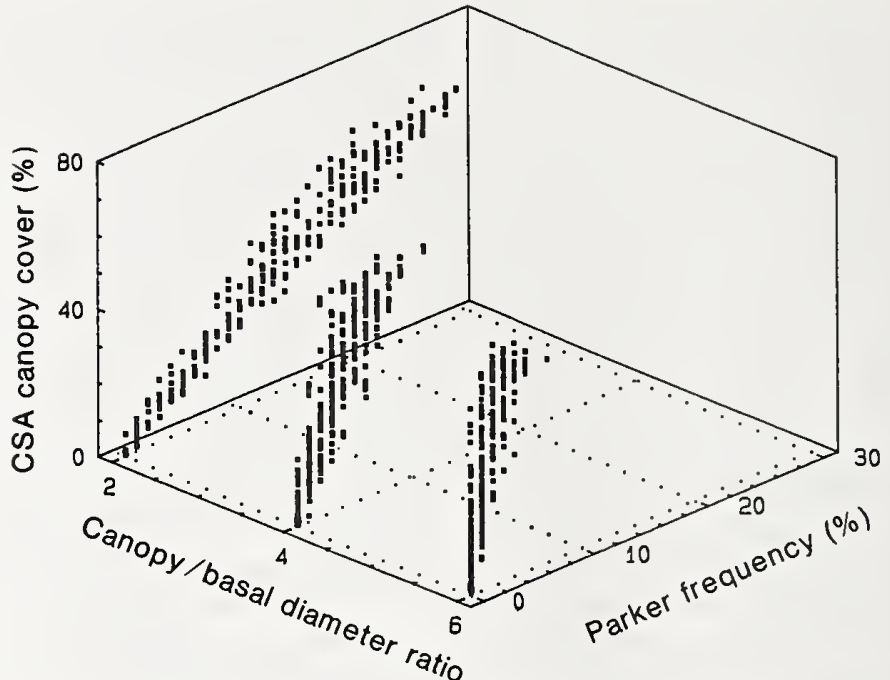

Figure 3.-Effect of canopy/basal diameter ratio on the relationship between CSA canopy cover and Parker frequency for plants with canopy/basal diameter ratios of 2, 4, and 6 .

\section{CSA Frequency and Parker Frequency Relationships}

The large difference in plot sizes used for measuring CSA frequency and Parker frequency $\left(0.5 \mathrm{~m}^{2}\right.$, and 3/4-inch diameter) and the differences in sample sizes of the two methods ( 10 plots and 100 plots per transect, respectively) resulted in CSA frequencies near $100 \%$ with Parker frequencies near $0 \%$. As a result, increasing basal area caused small changes in Parker frequency and large changes in CSA frequency (fig. 4). Parker frequency continued to increase long after CSA frequency had reached $100 \%$.

\section{Basal Area and Parker Frequency Relationships}

Computer simulations showed both CSA canopy cover and CSA density to be related to Parker frequency. Rela-



Figure 4.-Effect of basal diameter on the relationship between CSA frequency and Parker frequency for plants with basal diameters of 3,6 , and $12 \mathrm{~cm}$. 
tionships, however, were not simple and in both cases were dependent on basal area related parameters. Plotting CSA canopy cover, CSA density, and basal area measured using the 5 - by $10-\mathrm{cm}$ microplot on a relative scale against Parker frequency revealed a wide variation in relationships for the first two vegetation parameters with much less variation for basal area (fig. 5).

Analysis of these relationships indicated that the number of Parker hits obtained on a transect was a function of the basal area of the sample species. As the basal area of a species increased, the probability of its being "hit" also increased. Basal area was the vegetation parameter measurement most strongly and simply related to Parker frequency. However, numerous plant and vegetation community characteristics could potentially influence the functional form of the relationship between basal area and Parker frequency. These characteristics included mean plant size, variation in plant size, and grouping of plants within the community (random to highly contagious distributions).

\section{Plant Size Effects}

Mean plant basal diameter had a significant influence on the form of basal area and Parker frequency relation-

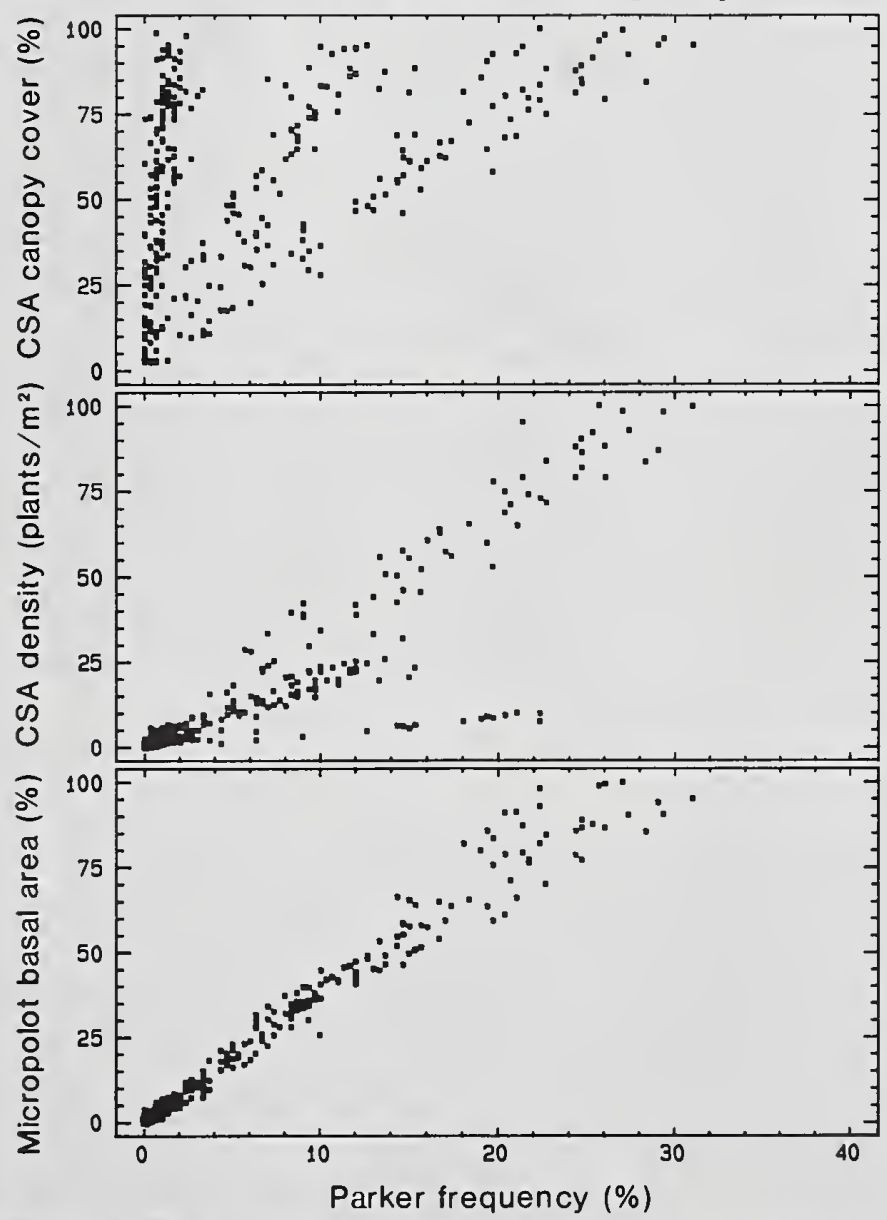

Figure 5.-Relationships between Parker frequency and percentages of maximum: CSA canopy cover (canopy/basal diameter ratios of 2 and 6); CSA density (mean basal dlameters of 3,6 , and $12 \mathrm{~cm}$ ); and microplot basal area (mean basal diameters of 3,6 , and $12 \mathrm{~cm})$.

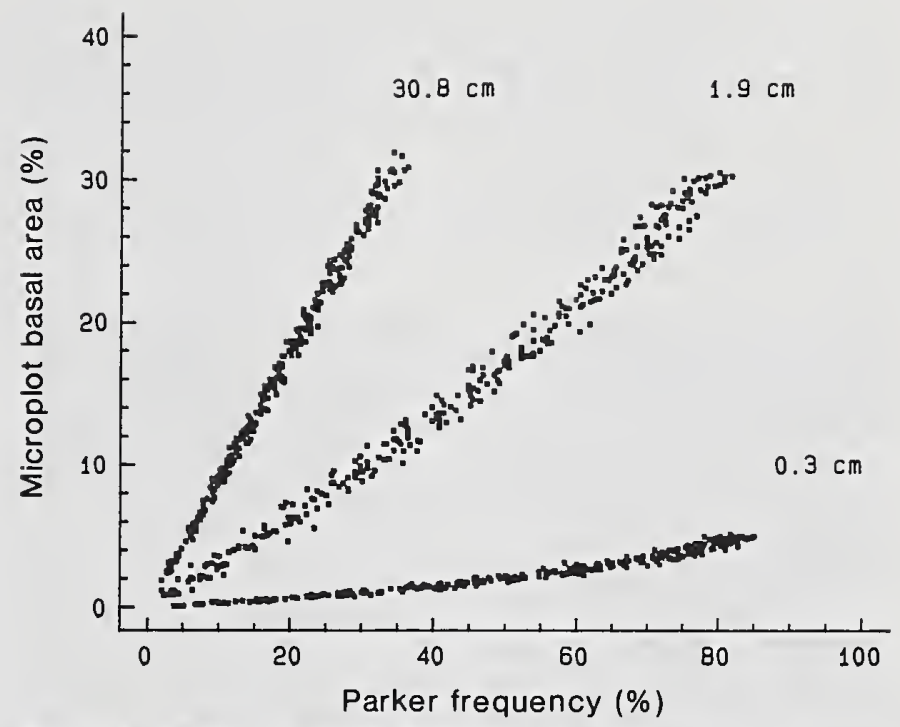

Figure 6.-Effect of basal diameter on relationships between microplot basal area and Parker frequency. Relationships are shown for plants with basal diameters of $0.3,1.9$, and $30.8 \mathrm{~cm}$.

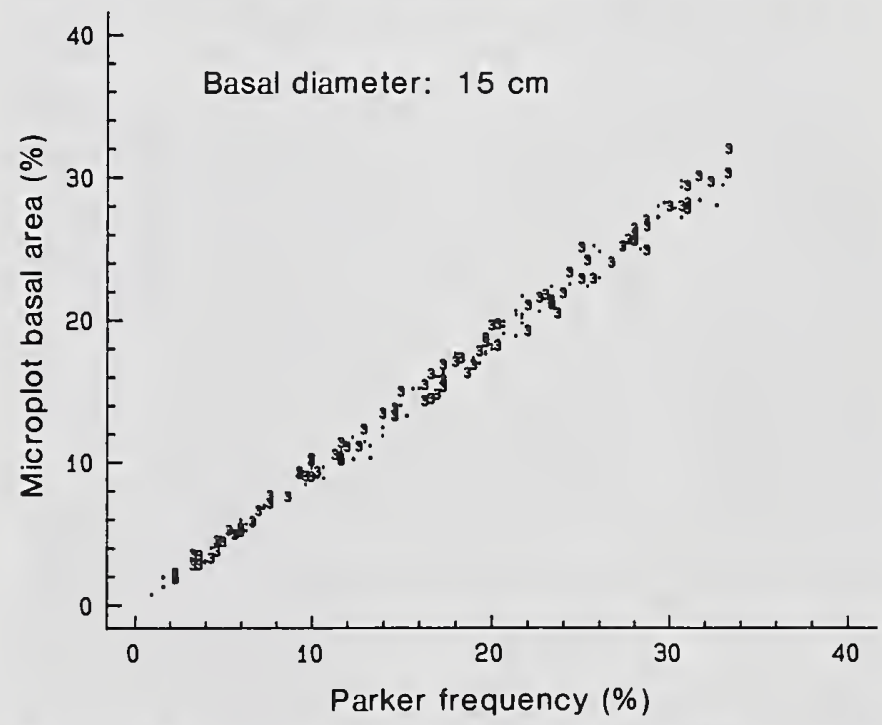

Figure 7.-Relationship between microplot basal area and Parker frequency for plants with a mean basal diameter of $15 \mathrm{~cm}$ and standard deviation of either $0 \mathrm{~cm}(\cdot)$ or $3 \mathrm{~cm}(3)$.

ships. Large plants (30.8- $\mathrm{cm}$ mean basal diameter, fig. 6) had a linear relationship between basal area and Parker frequency with a slope near 1 and a $Y$-intercept near zero. The smallest plant size tested $(0.3-\mathrm{cm}$ diameter, fig. 6) had a curvilinear relationship. Intermediate plant sizes had functional relationships between these two extremes.

\section{Plant-Size Variation Effects}

Results of simulations in which mean basal diameter was held constant and standard deviation of basal diameter was changed indicated no significant influence on the functional form of the relationship between basal area and Parker frequency. This was consistent with the findings of Hutchings and Holmgren (1959). For exam- 
ple, no differences in CSA basal area and Parker frequency relationships were evident for simulations of 15-cm mean basal diameter plants with standard deviations of 0 and $3 \mathrm{~cm}$. Regressions fit to these data sets were similar, and plotting these data on the same graph (fig. 7) illustrated the overlap of data points that typified this and other simulation tests concerning variation in plant size.

a

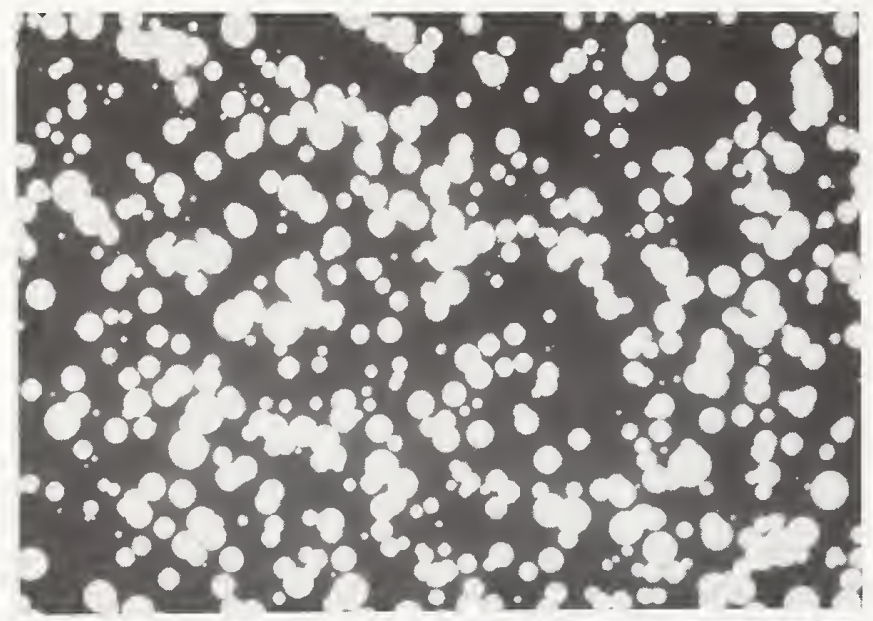

b

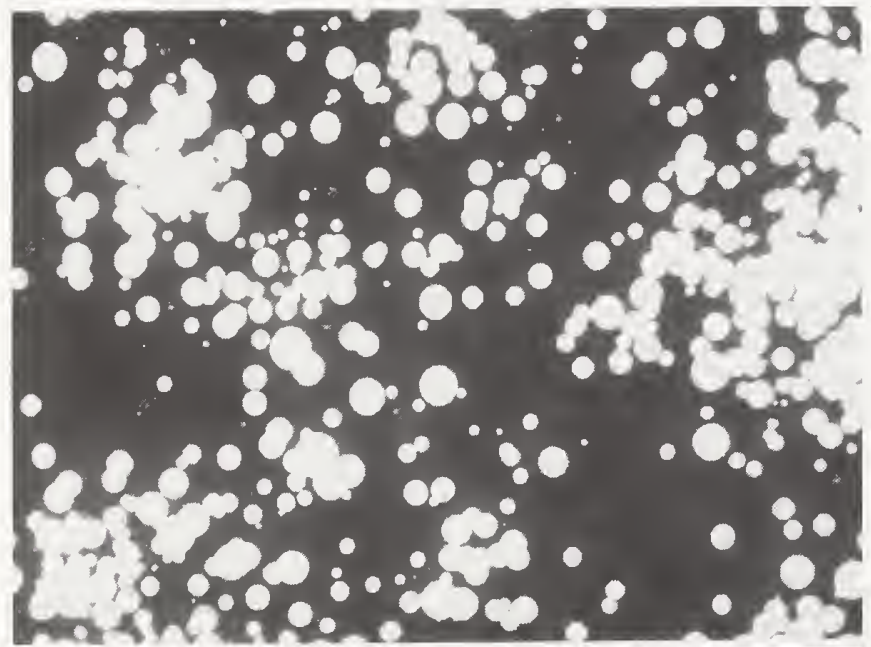

C

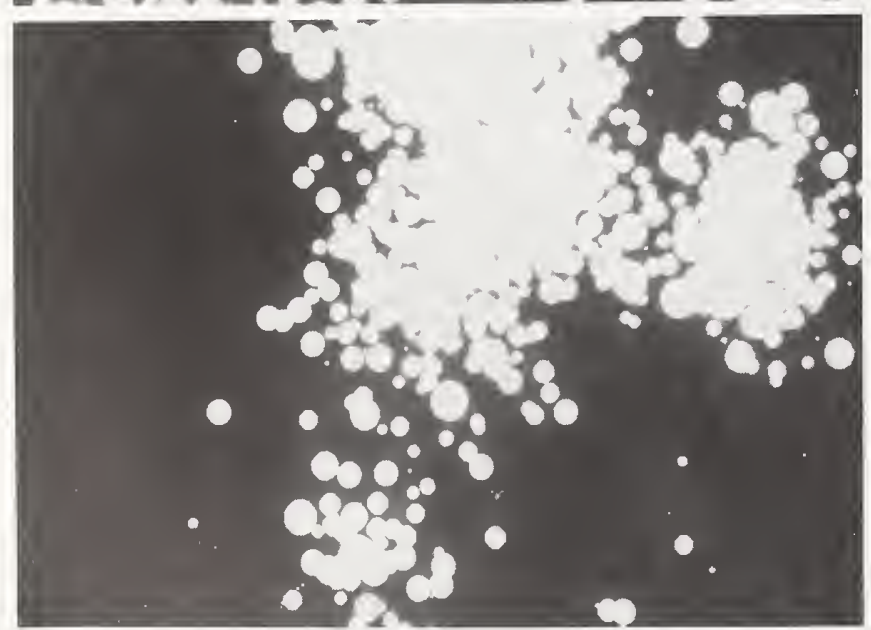

Figure 8.-Photographs of artificial vegetation maps with various distributions of plant individuals: (a) random population (no contagion); (b) intermediately contagious population; and (c) heavily contagious population.

\section{Plant Distribution Effects}

Plant species are seldom randomly distributed within plant communities. Rather, they show at least some contagion ("clumping") in their pattern of distribution. Simulations were run in which the degree of contagion of individuals of a plant species varied from random to highly contagious. Random populations showed no contagion (fig. 8a). Populations with intermediate contagion (fig. 8b) showed individuals beginning to form into groups but with less intensity than for heavily contagious populations. Populations with heavy contagion had most plants gathered into a few groups ( 3 to 5) with large empty spaces between groups (fig. 8c).

The degree of contagion of a population was sometimes a significant variable, especially when an extremely contagious population was compared with a completely random population. Therefore, the relationship between CSA basal area and Parker frequency may depend on the degree of contagion within the community. Simulations of 3-cm and 9-cm basal diameter plant communities with different contagions illustrated the effects. Simple linear regressions for populations with a mean basal diameter of $3 \mathrm{~cm}$ and distributions ranging from random to heavily contagious (fig. 9) resulted in

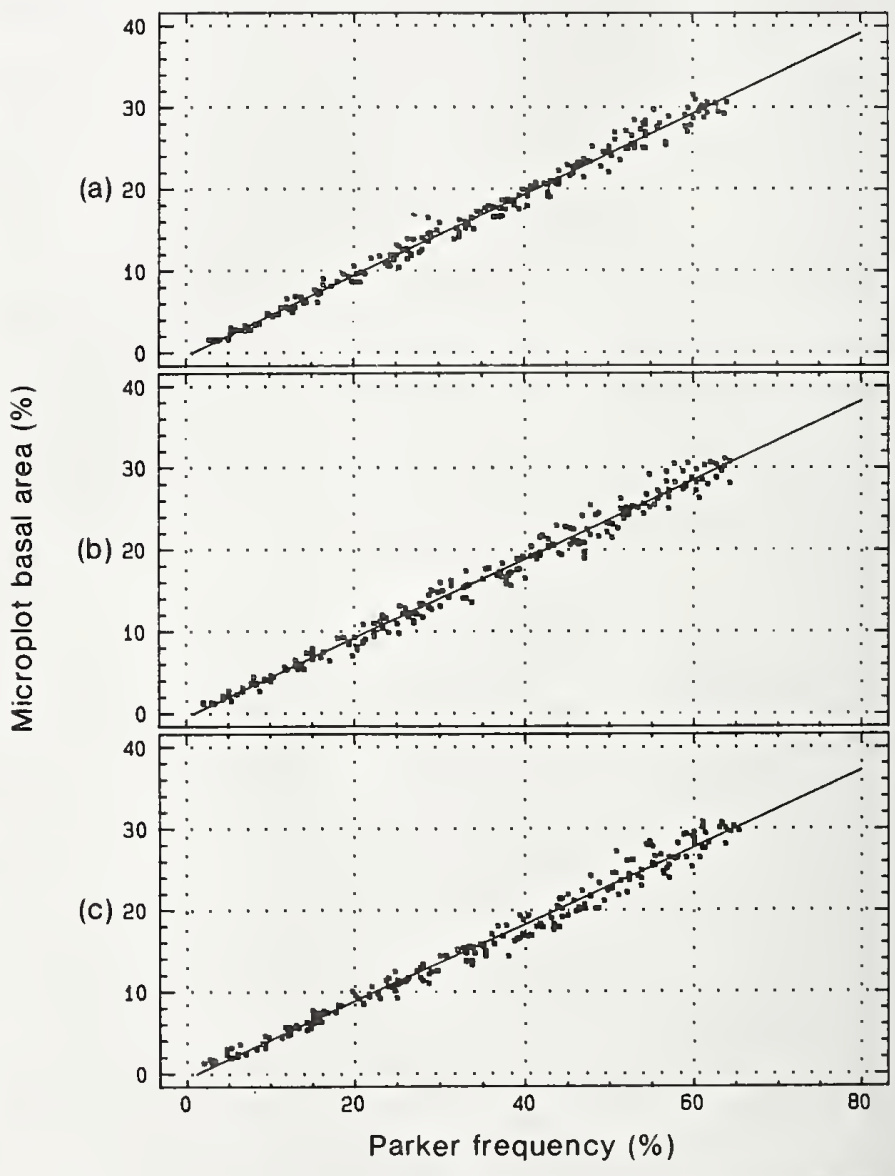

Figure 9.-Relationship between microplot basal area and Parker frequency for populations with various distributions of $3-\mathrm{cm}$ basal diameter plants: (a) random population (no contagion); (b) intermediately contagious population; and (c) heavily contagious population. 
no overlap of the $95 \%$ confidence limits for slope for the entirely random and heavily contagious populations (table 1).

For small plants, such as this 3-cm example, the effect of heavy contagion was to shift the regression line upward relative to that observed for a random population. The slope for a 3-cm basal diameter population with intermediate contagion fell between slopes observed for random and heavily contagious populations. In addition, the $95 \%$ confidence limits for slope from the population with intermediate contagion overlapped confidence limits for slopes from both random and heavily contagious populations (table 1).

Simple linear regression for populations with a mean basal diameter of $9 \mathrm{~cm}$ and distributions that were random, intermediately contagious, and heavily contagious resulted in overlap in the $95 \%$ confidence limits for slope from random, intermediately contagious, and heavily contagious populations (table 1). Larger plants, such as this 9-cm example, had less contagion effect.

Differences in the relationship between random and contagious populations were most apparent as mean plant size became small (on the order of $3 \mathrm{~cm}$ or less). Plants with larger mean basal diameters exhibited less contagion effect. However, for any population, differences in predicted basal areas because of contagion were minimal for mean Parker hits in the range of 1 to approximately 20 . When relationships between mean Parker hits and basal area for populations with intermediate contagion were examined, data sets were found to overlap such that prediction limits for basal area from populations with intermediate contagion included much of the data sets from either random or heavily contagious populations, especially where mean number of Parker hits was less than 20 or when mean plant basal diameters exceeded $3 \mathrm{~cm}$.

Most perennial plant species of interest were presumed to exhibit neither random nor heavily contagious distributions. Therefore, populations of intermediate contagion were used in the development of prediction equations. Subjective information contained within Parker records should indicate whether or not this assumption could be met.

\section{Number of Transects}

Error bounds on predictions of basal area were significantly influenced by whether samples taken were composed of single Parker transects (100 plots) or clusters of three transects (300 plots). Comparisons of regressions of actual basal area against Parker frequency showed a decrease in error mean square and an increase in $R^{2}$ when sample size was increased from a transect to a cluster (figs. 10 and 11). For example, note the narrowing of prediction limits for a new observation (the outer set of lines paralleling the regression line) for a sample size of one cluster (fig. 11) as compared to a sample size of one transect (fig. 10). Using these regressions, if the observed number of Parker hits from a single transect was 20 , then the predicted value of basal area would fall between approximately $11 \%$ and $20 \%$ (fig. 10). Had the number of Parker hits been estimated based on a cluster (300 points) rather than a single transect, then basal area would be predicted to fall between $13 \%$ and $18 \%$ (fig. 11).

Reductions in prediction limits such as those observed in the above example may be critical when attempting to determine changes in vegetation over time. Parker data from one transect were observed to be highly variable when compared to data from three or more transects рег cluster. The number of transects actually installed per cluster in the field was dependent on the number of "hits" on live perennial vegetation per transect and varied from one to three. Nevertheless, our recommendation would be to limit analysis to situations where data were collected from homogeneous Parker clusters containing at least three transects because of the unacceptably high variation associated with one or two transects per cluster.

The effect of increasing sample size on accuracy and precision of basal area was similar to that observed for Parker frequency. Prediction limits for actual basal area are narrowed as the sample size increases from one transect to one cluster (figs. 12 and 13).

\section{Prediction Equations and Prediction Tables}

A regression model $\sqrt{Y}=\sqrt{a+b\left(X^{d}\right)}$ of the transformboth-sides methodology of Carroll and Ruppert (1988) best explained the relationship between Parker frequency $(X)$ and basal area $(Y)$, where the exponent $d$ was related to basal diameter. This model removed heteroscedasticity and provided a normal distribution of residuals that permitted the use of standard statistical tests and prediction limits. Prediction equations assumed populations of intermediate contagion, and data represented total hits from one Parker cluster (three Parker transects). (See appendix A for information on equations.)

To simplify the interpretation of predictions from Parker data, a table was developed (appendix B, already transformed) that allows prediction of percent basal area (as would be estimated by the CSA method) for given mean plant sizes and total number of Parker hits from three transects (one cluster). For example, if the mean basal diameter of a species was estimated to be approximately $8 \mathrm{~cm}$, then appendix $B$ would be consulted, the basal diameter would be located, and the total number of Parker hits would be located in the left-hand column. The appropriate prediction information of basal area would be read directly from the table. Information available includes the predicted percent mean basal area and $95 \%$ prediction limits around the mean for a new observation. Note that the prediction limits are not symmetrical about the mean because of the nonlinear transformation used in the regression model. If a mean plant size or number of Parker hits is not represented in appendix B, interpolation between the closest values would be necessary. Care should be taken if total Parker hits (by species) for the cluster exceed 90 (out of 300 pos- 
Table 1.-Comparison of confidence intervals for slope parameters for 3-cm and 9-cm basal diameter plants with various community patterns of plant distribution.

\begin{tabular}{lccc}
\hline \multicolumn{1}{c}{ Contagion } & Y-intercept & \multicolumn{2}{c}{$95 \%$ confidence limit on slope } \\
\cline { 4 - 4 } & & Lower limit & Upper limit \\
\hline 3-cm-diameter plants & & & \\
Random & -0.55447 & 0.46270 & 0.48060 \\
Intermediate & -0.45024 & 0.47388 & 0.49167 \\
Heavy & -0.37691 & 0.48694 & 0.50192 \\
9-cm-diameter plants & 0.08700 & 0.69711 & 0.71613 \\
Random & 0.13449 & 0.70661 & 0.72743 \\
Intermediate & 0.09598 & 0.69974 & 0.72153 \\
Heavy & & & \\
\hline
\end{tabular}

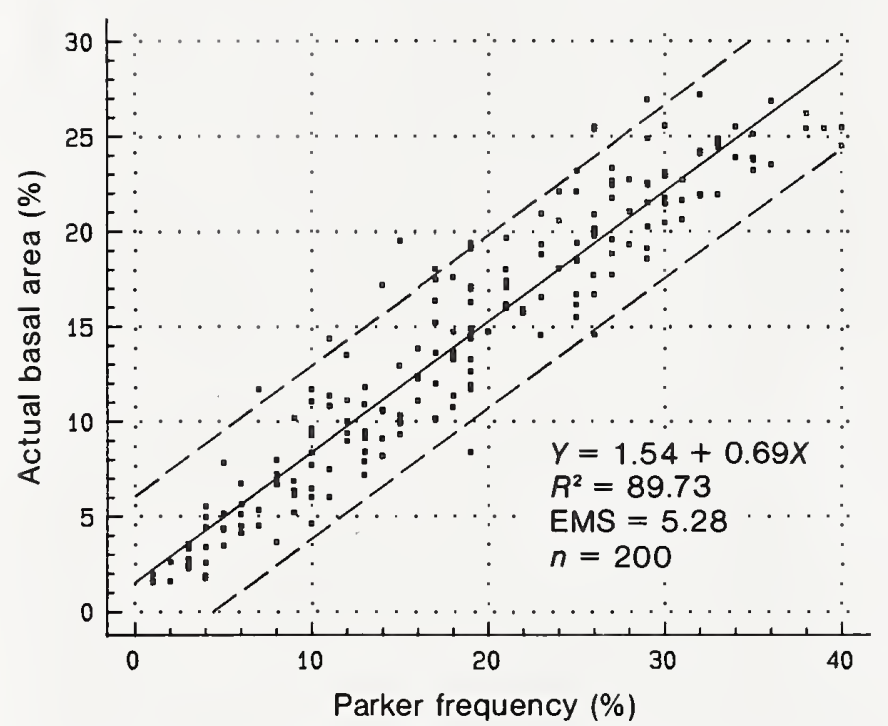

Figure 10.-Relationship between actual basal area and Parker frequency for a sample from a single Parker transect. Plants had a $9-\mathrm{cm}$ basal diameter. Outer lines represent $95 \%$ prediction limits for a new observation.

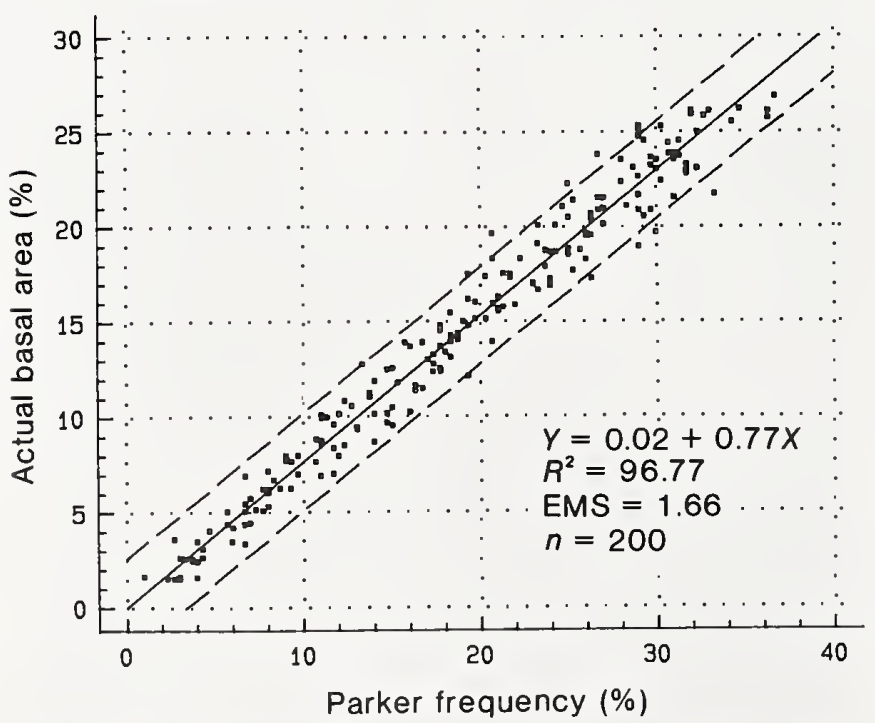

Figure 11.-Relationship between actual basal area and Parker frequency for a sample from a single Parker 3-transect cluster. Plants had a $9-\mathrm{cm}$ basal diameter. Outer lines represent $95 \%$ prediction limits for a new observation.

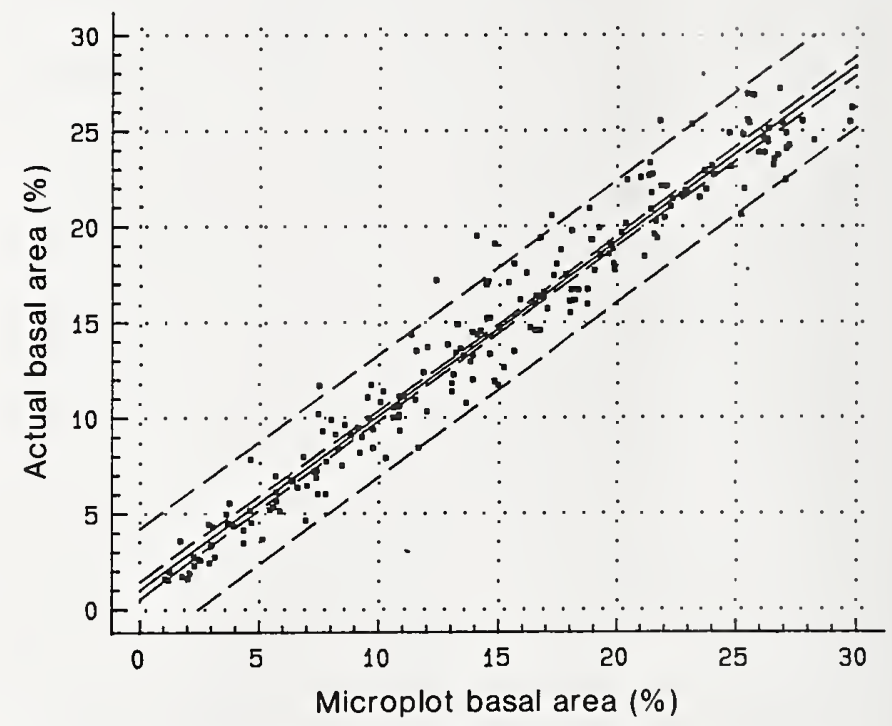

Figure 12.-Relationship between actual basal area and microplot basal area for a sample from a single Parker transect. Plants had a $9-\mathrm{cm}$ basal diameter. Outer lines represent $95 \%$ prediction limits for a new observation.

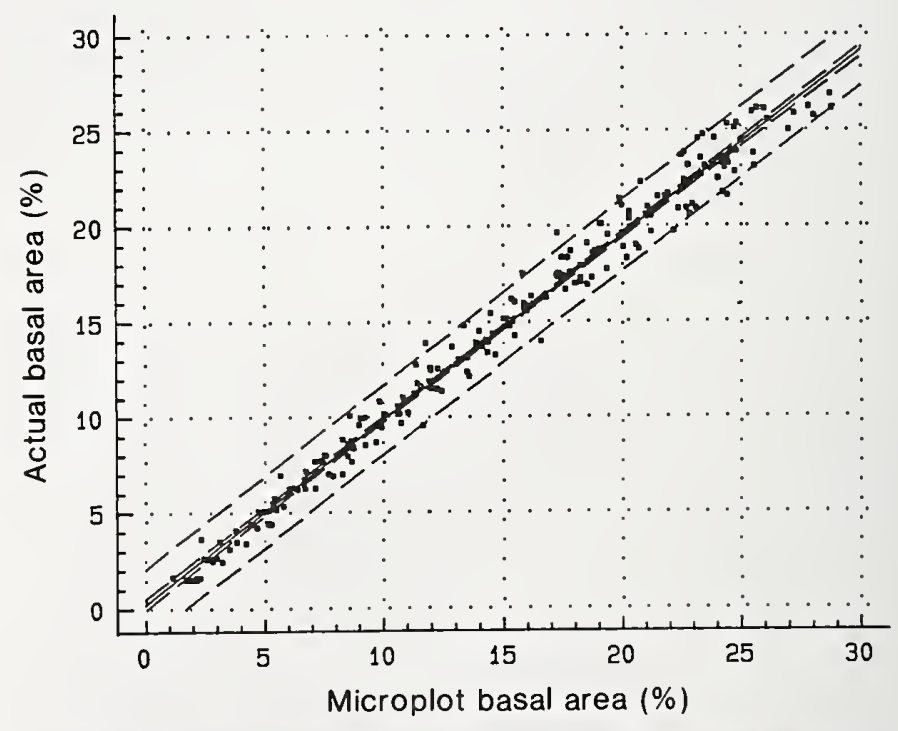

Figure 13.-Relationship between actual basal area and microplot basal area for a sample from a single Parker 3-transect cluster. Plants had a $9-\mathrm{cm}$ basal diameter. Outer lines represent $95 \%$ prediction limits for a new observation. 
sible hits) because extrapolations beyond these limits may be inaccurate, particularly for smaller plant sizes.

Slopes of prediction equations (from appendix A) were plotted against Parker frequency for mean plant diameters between 0.3 and $33.6 \mathrm{~cm}$ (fig. 14). Smaller plants had considerable differences between slopes of prediction lines. However, larger plant sizes had smaller differences between slopes. Therefore, as mean plant diameter increased, the slope of the prediction line also increased but at a decreasing rate. For these same equations the $Y$-intercepts were grouped around zero (fig. 15). A practical consequence of this relationship was that the accurate estimation of mean basal diameter became increasingly important for smaller plants.

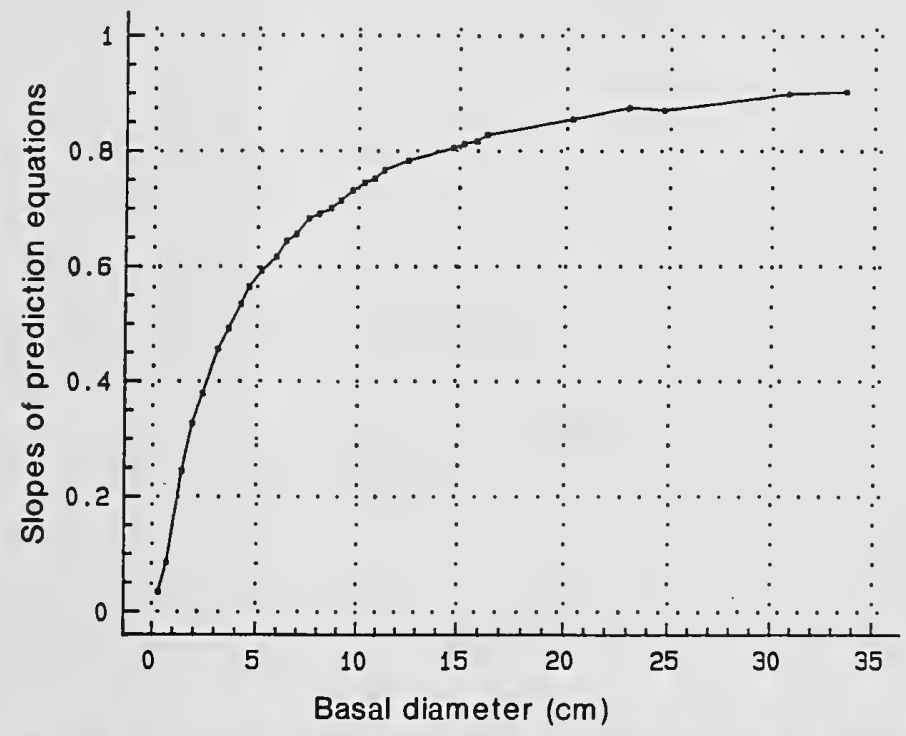

Figure 14.-Slopes of equations used in construction of the basal area prediction table (appendix B) as related to mean plant basal diameter.

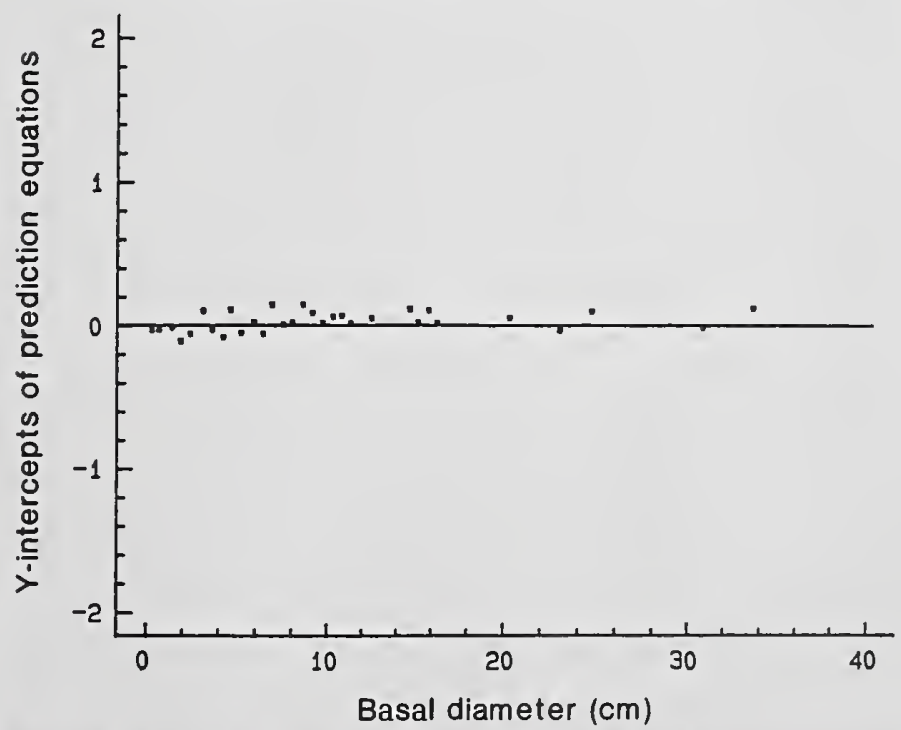

Figure 15. -Y-intercepts of equations used in constructlon of the basal area prediction table (appendix B) as related to mean plant basal diameter.
Table 2.-Comparison of actual basal areas of communities of paper disks with basal areas from the prediction table. Predicted basal areas were determined by inputting total Parker hits from 3-transect clusters into prediction tables.

\begin{tabular}{lrr}
\hline \multirow{2}{*}{$\begin{array}{l}\text { Total } \\
\text { Parker } \\
\text { hits }\end{array}$} & \multicolumn{2}{c}{ Basal area } \\
\cline { 2 - 3 } & Predicted & Actual \\
\hline $\begin{array}{l}\text { 15.2-cm basal diameter paper disks } \\
78\end{array}$ & 21.21 & \\
78 & 21.21 & 20.00 \\
68 & 18.48 & 20.00 \\
66 & 17.93 & 16.40 \\
47 & 12.76 & 16.40 \\
43 & 11.66 & 10.40 \\
16 & 4.33 & 10.40 \\
16 & 4.33 & 5.40 \\
$15.2-\mathrm{cm}$ basal diameter paper disks & & 5.40 \\
68 & 18.48 & \\
64 & 17.39 & 19.69 \\
54 & 14.66 & 19.69 \\
53 & 14.39 & 17.64 \\
$22.6-\mathrm{cm}$ basal diameter paper disks & & 17.64 \\
104 & $>26.24$ & \\
63 & 18.30 & 25.30 \\
34 & 9.83 & 16.40 \\
10 & 2.90 & 7.50 \\
& & 3.30 \\
\hline
\end{tabular}

\section{Empirical Validation of Prediction Equations}

Three independent tests of reliability of the prediction equations were conducted using populations of $22.6-\mathrm{cm}-$ and 15.2-cm-diameter paper disks to simulate plant populations. Paper disks were used because percent basal area could be measured with little error. Samples from these populations were collected using standard Parker and CSA protocols and equipment. Predictions generally fell within $2 \%$ of actual basal areas, and only 1 prediction out of a total of 16 exceeded a difference of $3 \%$ (table 2 ).

A procedure described by Freese (1960) and Reynolds (1984) was used to check the accuracy of the prediction table (appendix B, $15.2-\mathrm{cm}-, 20.3-\mathrm{cm}-$, and $23-\mathrm{cm}-$ diameter plants). With a Type I error probability level of 0.05 , the estimated basal areas were within $2.5 \%$, $3.5 \%$, and $3 \%$ of the true (paper disk) values for these tests.

\section{Conclusions and Recommendations}

Our results indicated that a relationship did exist between Parker frequency data and data collected using the CSA protocol. The best (i.e., strongest and simplest) relationship was between Parker data and percent basal area measured with the CSA microplot. Equations relating these data types are presented in appendix A. Preliminary tests of accuracy of the prediction table (appendix B) that was created from the regression equations gave satisfactory results. However, a great deal of variability characterized Parker data, and it is necessary to interpret results only in terms of long-term vegetation trends. 
The collection of additional Parker data is not recommended. However, we would advocate the use of the prediction table (appendix B) to convert previously collected Parker data into a basal area format, thus improving the manager's ability to ecologically interpret change. Assumptions that must be made when using prediction tables include: (1) Parker data comes from a cluster containing three transects on a homogeneous site; (2) basal diameter of the species of interest can be predicted; (3) shape of the species does not strongly deviate from a circular polygon; and (4) distribution of the species was neither random nor strongly contagious. Results are highly sensitive to assumptions (1), (2), and (3) and are relatively insensitive to assumption (4). Additional work needs to be done on plant shape.

Sample size was also an important consideration in obtaining useful results. Our simulations indicated that Parker frequency data should be collected from groups of at least three Parker transects (300 points or one cluster). Prediction equations assume this sample size. Smaller sample sizes (i.e., one or two transects) did not give satisfactory precision. This was particularly true for Parker frequency data but was also true for CSA data.

Conversion of past Parker records to a percent basal area format may assist managers in understanding what historical changes, if any, have occurred on rangelands. It should be emphasized that interpretation of basal area predictions from historical Parker data are intended to be used only to understand long-term historical vegetation trend, since numerous variables influence our ability to accurately assess vegetation changes. Availability of subjective information collected as part of the Parker 3-step method provides valuable historical data that should aid in validation of long-term predicted vegetation trends.

Basal area prediction tables such as the ones presented may provide a bridge between the Parker procedure of the past and sampling designs used for future monitoring programs. Old Parker records may be converted to a form equivalent to more ecologically meaningful and statistically reliable vegetation measurements, thus assuring a continuity of data over time.

\section{Literature Cited}

Aberdeen, J. E. C. 1958. The effect of quadrat size, plant size, and plant distribution on frequency estimates in plant ecology. Australian Journal of Botany. 6: 47-58.

Brady, Ward W. 1988. Relationships between data collected using the Parker 3-step method and the Community Structure Analysis method. Final report submitted to the Rocky Mountain Forest and Range Experiment Station, Albuquerque, New Mexico.

Carroll, R. J.; Ruppert. D. 1988. Transformation and weighting in regression. New York, NY: Chapman and Hall. 249 p.

Daubenmire, Rexford. 1968. Plant communities. New York, NY: Harper and Row. 300 p.
Francis, Richard E.; Driscoll, Richard S.; Reppert, Jack N. 1972. Loop-frequency as related to plant cover, herbage production, and plant density. Res. Pap. RM-94. Fort Collins, CO: U.S. Department of Agriculture, Forest Service, Rocky Mountain Forest and Range Experiment Station. $8 \mathrm{p}$.

Freese, F. 1960. Testing accuracy. Forest Science. 6: 139-145.

Greig-Smith, P. 1983. Quantitative plant ecology. 3rd ed. Berkeley, CA: University of California Press. 359 p.

Hutchings, Selar S.; Holmgren, Ralph C. 1959. Interpretation of loop-frequency data as a measure of plant cover. Ecology. 40: 668-677.

Johnston, A. 1957. A comparison of the line interception, vertical point quadrat, and loop methods as used in measuring basal area of grassland vegetation. Canadian Journal of Plant Science. 37: 34-42.

Kinsinger, Floyd E.; Eckert, Richard E.; Currie, Pat O. 1960. A comparison of the line-interception, variableplot and loop methods as used to measure shrubcrown cover. Journal of Range Management. 13: 17-21.

Morris, Meredith. 1973. Estimating understory plant cover with rated microplots. Res. Pap. RM-104. Fort Collins, CO: U.S. Department of Agriculture, Forest Service, Rocky Mountain Forest and Range Experiment Station. $12 \mathrm{p}$.

Neter, John; Wasserman, William; Kutner, Michael H. 1985. Applied linear statistical models. Homewood, IL: Irwin. 1127 p.

Parker, Kenneth W. 1950. Report on 3-step method for measuring condition and trend of forest ranges. Admin. Rep. Washington, DC: U.S. Department of Agriculture, Forest Service. 68 p.

Parker, Kenneth W. 1951. A method for measuring trend in range condition on national forest ranges. Fort Collins, CO. U.S. Department of Agriculture, Forest Service, Rocky Mountain Forest and Range Experiment Station. 26 p.

Parker, Kenneth W.; Harris, Robert W. 1959. The 3-step method for measuring condition and trend of forest ranges: a resume of its history, development, and use. In: Techniques and methods of measuring understory vegetation: proceedings of a symposium; 1958 October; Tifton, GA. Washington, DC: U.S. Department of Agriculture, Forest Service, Southern Forest and Range Experiment Station, and Southeastern Forest and Range Experiment Station: 55-69.

Pase, Charles P. 1981. Community structure analysis-a rapid, effective range condition estimator for semi-arid ranges. In: Arid land resource inventories: developing cost-efficient methods: proceedings of an international workshop; 1980 November 30-December 6; La Paz, Mexico. Gen. Tech. Rep. WO-28. Washington, DC: U.S. Department of Agriculture, Forest Service: 425-430.

Reppert, Jack N.; Francis, Richard E. 1973. Interpretation of trend in range condition from 3-step data. Res. Pap. RM-103. Fort Collins, CO: U.S. Department of Agriculture, Forest Service, Rocky Mountain Forest and Range Experiment Station. 15 p. 
Reynolds, M. R., Jr. 1984. Estimating the error in model predictions. Forest Science. 30: 454-469.

Sharp, Lee A. 1954. Evaluation of the loop procedure of the 3-step method in the salt-desert shrub type of southern Idaho. Journal of Range Management. 7: 83-88.

Smith, Justin G. 1962. An appraisal of the loop transect method for estimating root crown area changes. Journal of Range Management. 15: 72-78.
Statgraphics. 1989. Statistical Graphics System version 3.0. Statistical Graphics Corporation (STSC), Inc., 2115 E. Jefferson St., Rockville, MD 20852.

West, Neal E. 1985. Shortcomings of plant frequencybase methods for range condition and trend. In: Use of frequency and density for rangeland monitoring: proceedings of the 38th annual meeting of the Society for Range Management; 1985 February 11-15; Salt Lake City, UT. Society for Range Management: 87-90.

Appendix A: Regression Equations

Prediction equation coefficients for model: $\sqrt{\text { basal area }}=a+b(\sqrt{\text { Parker frequencyd }})$.

\begin{tabular}{|c|c|c|c|c|}
\hline \multirow{2}{*}{$\frac{\begin{array}{c}\text { Basal } \\
\text { diameter }\end{array}}{(\mathrm{cm})}$} & \multirow[b]{2}{*}{$\mathbf{N}$} & \multicolumn{3}{|c|}{ Coefficients } \\
\hline & & Intercept (a) & Slope (b) & Exponent (d) \\
\hline 0.3 & 414 & 0.09918 & 0.04928 & 1.30 \\
\hline 0.7 & 414 & 0.09606 & 0.20994 & 1.15 \\
\hline 1.4 & 417 & 0.23556 & 0.32610 & 1.20 \\
\hline 1.9 & 421 & 0.12468 & 0.46489 & 1.10 \\
\hline 2.4 & 450 & 0.19079 & 0.49021 & 1.10 \\
\hline 3.1 & 403 & 0.20212 & 0.54144 & 1.10 \\
\hline 3.6 & 408 & 0.20152 & 0.56346 & 1.10 \\
\hline 4.2 & 405 & 0.28508 & 0.53050 & 1.15 \\
\hline 4.6 & 414 & 0.24093 & 0.60178 & 1.10 \\
\hline 5.2 & 418 & 0.21785 & 0.61722 & 1.10 \\
\hline 5.9 & 426 & 0.14617 & 0.68038 & 1.07 \\
\hline 6.4 & 404 & 0.17804 & 0.66484 & 1.09 \\
\hline 6.9 & 427 & 0.22003 & 0.66759 & 1.09 \\
\hline 7.5 & 421 & 0.21184 & 0.67962 & 1.09 \\
\hline 8.1 & 404 & 0.12070 & 0.74757 & 1.05 \\
\hline 8.6 & 402 & 0.18947 & 0.71882 & 1.07 \\
\hline 9.1 & 395 & 0.12464 & 0.77125 & 1.04 \\
\hline 9.7 & 405 & 0.16117 & 0.73884 & 1.07 \\
\hline 10.3 & 407 & 0.04322 & 0.84374 & 1.01 \\
\hline 10.8 & 438 & -0.04769 & 0.90585 & 0.98 \\
\hline 11.3 & 411 & 0.20873 & 0.73425 & 1.08 \\
\hline 12.5 & 337 & 0.02709 & 0.86786 & 1.01 \\
\hline 14.7 & 421 & 0.17914 & 0.78705 & 1.06 \\
\hline 15.2 & 443 & 0.02241 & 0.88434 & 1.01 \\
\hline 15.8 & 441 & -0.00827 & 0.92327 & 0.99 \\
\hline 16.3 & 454 & 0.07405 & 0.85626 & 1.03 \\
\hline 20.3 & 443 & 0.07978 & 0.86870 & 1.03 \\
\hline 23.0 & 436 & 0.04542 & 0.89701 & 1.02 \\
\hline 24.7 & 439 & -0.00479 & 0.93667 & 1.00 \\
\hline 30.8 & 447 & -0.00996 & 0.94571 & 1.00 \\
\hline 33.6 & 457 & 0.04615 & 0.53362 & 1.01 \\
\hline
\end{tabular}

$R^{2}$ values for these regressions ranged between $95.04 \%$ and $99.61 \%$. 


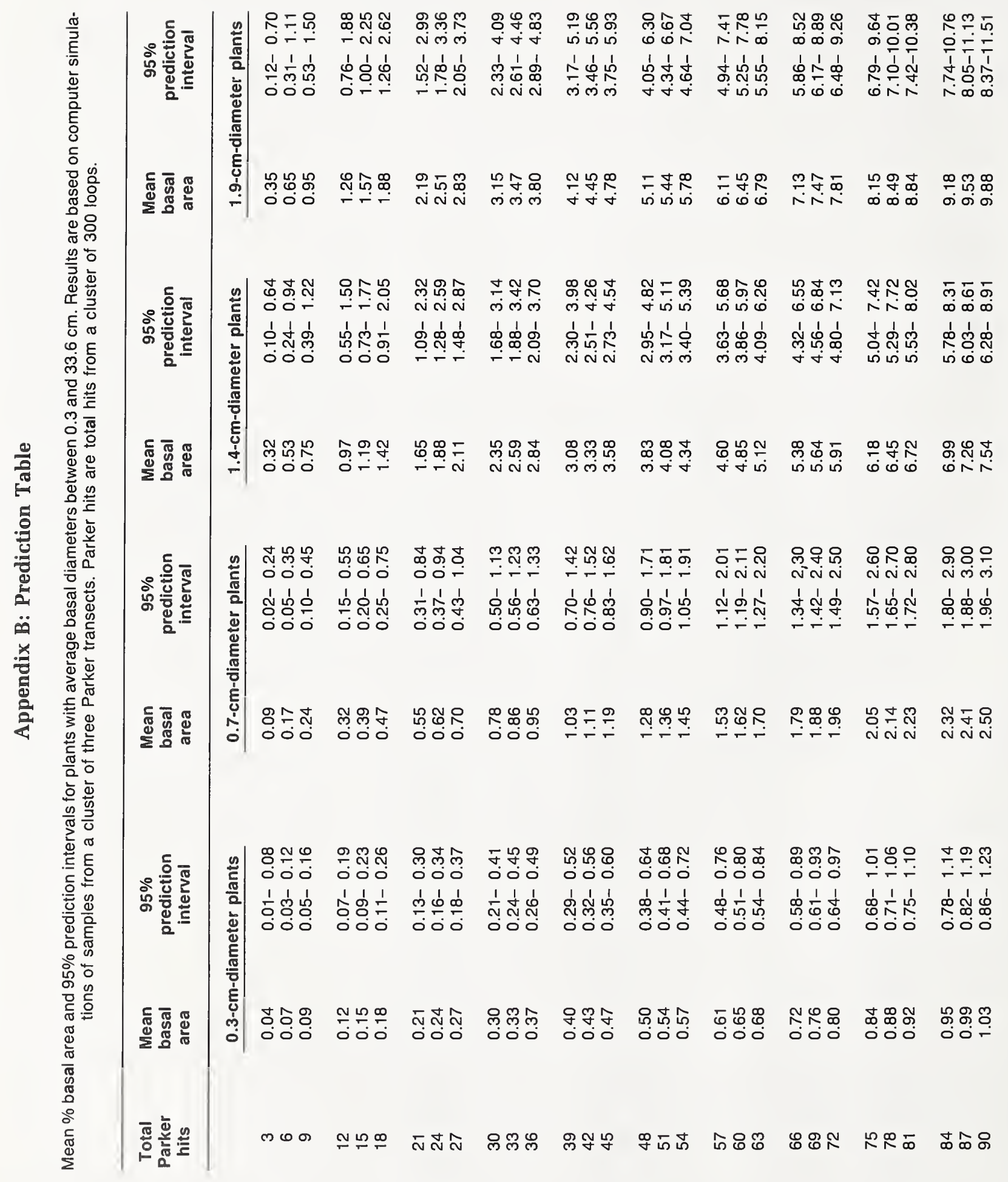




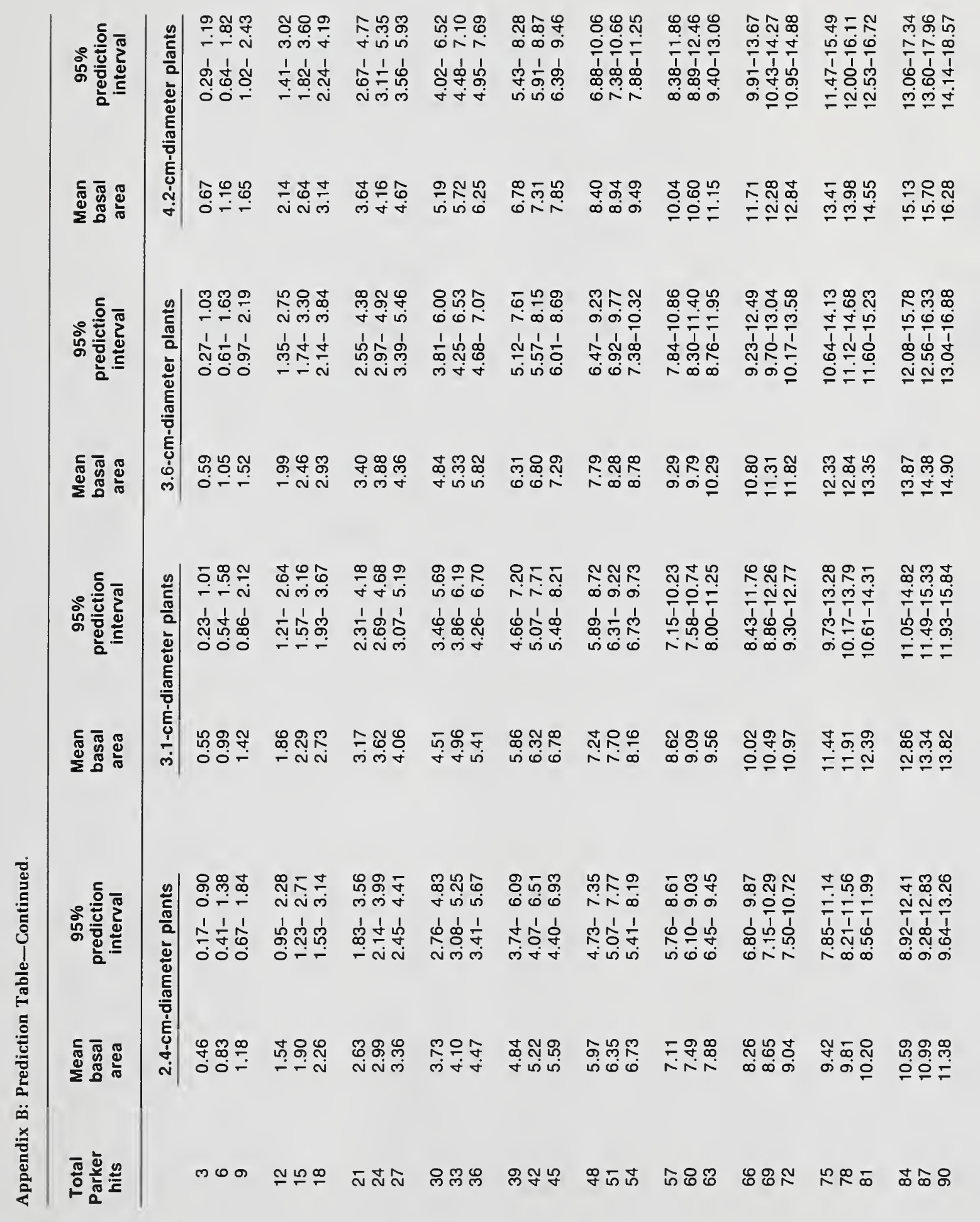




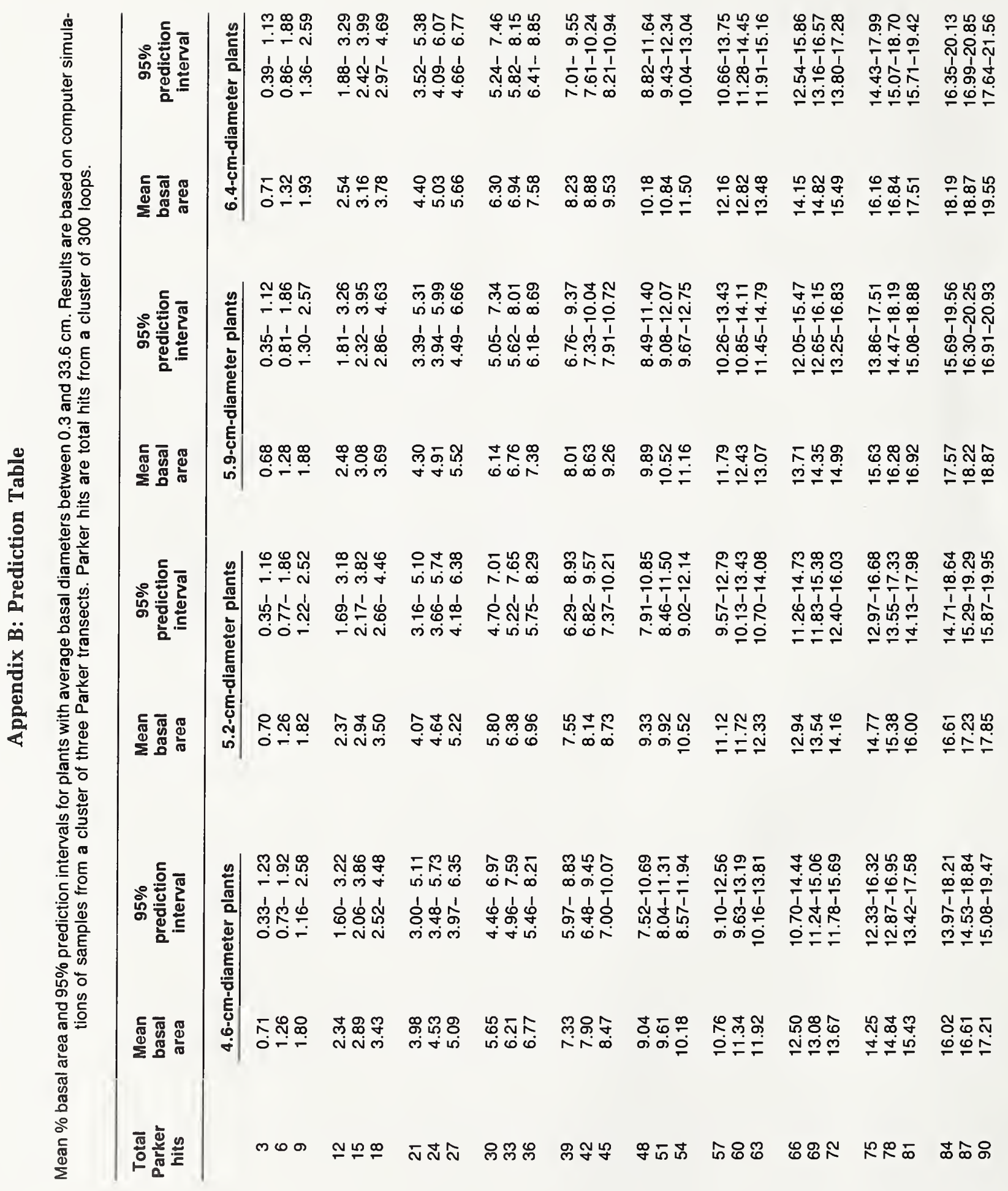




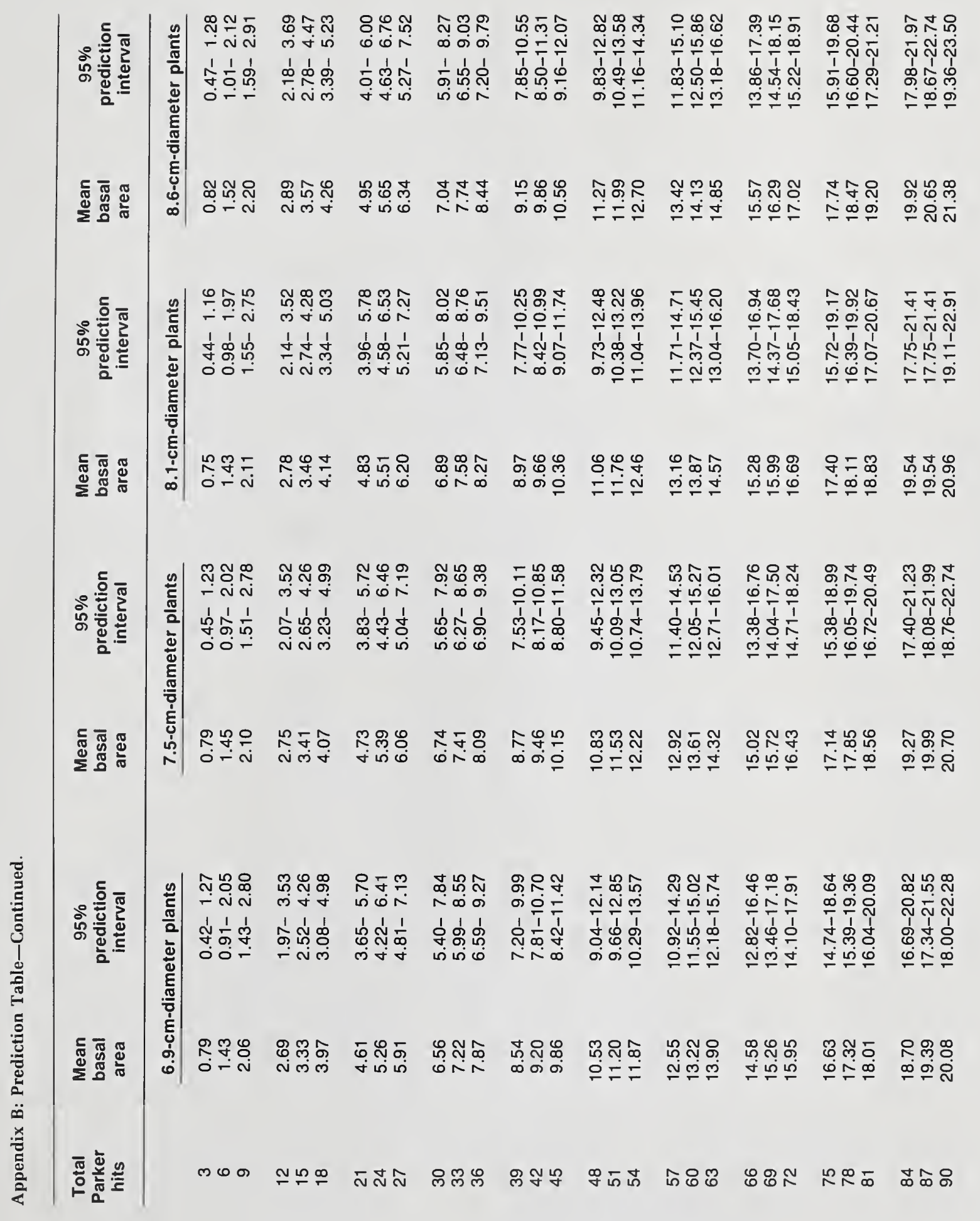




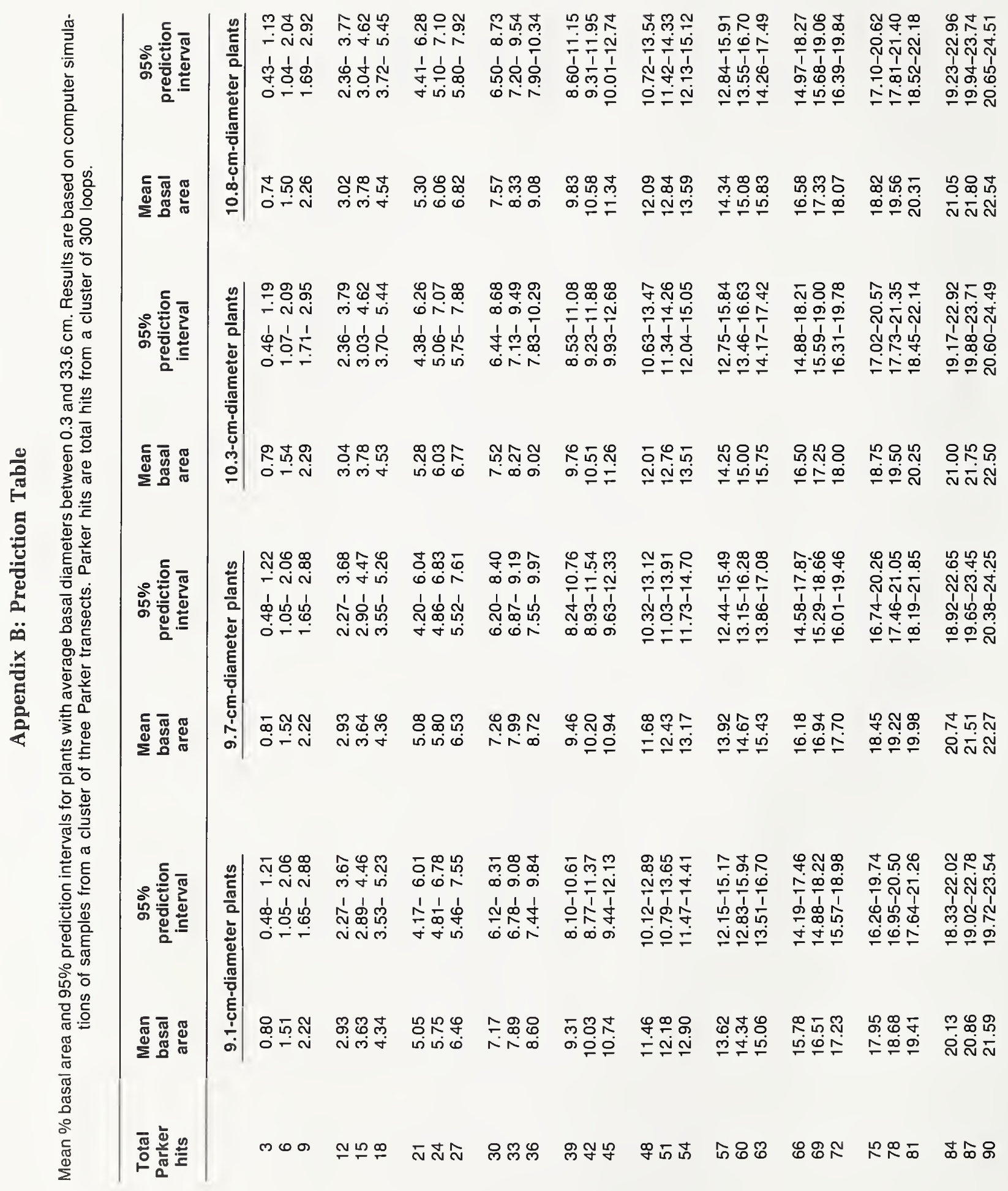




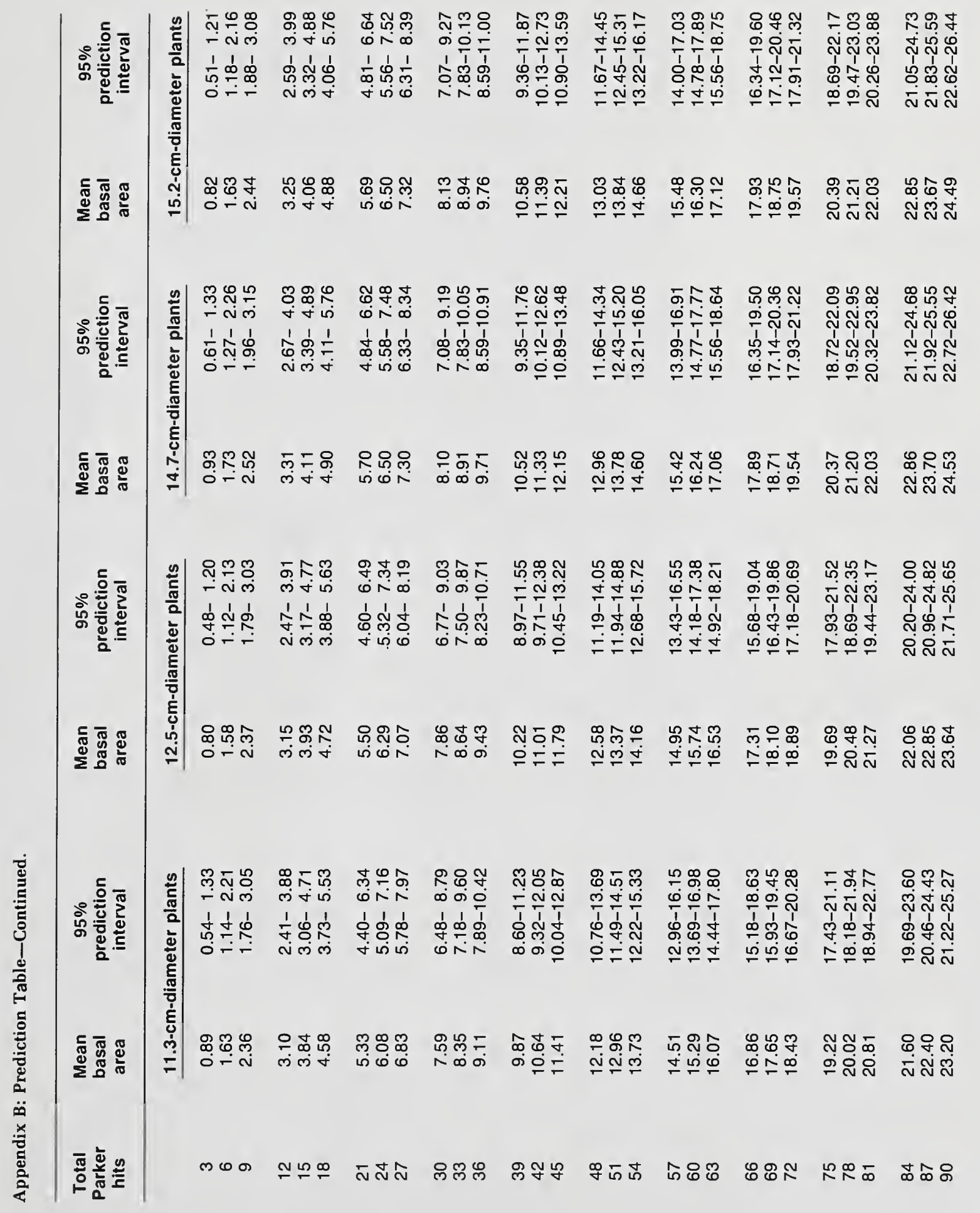




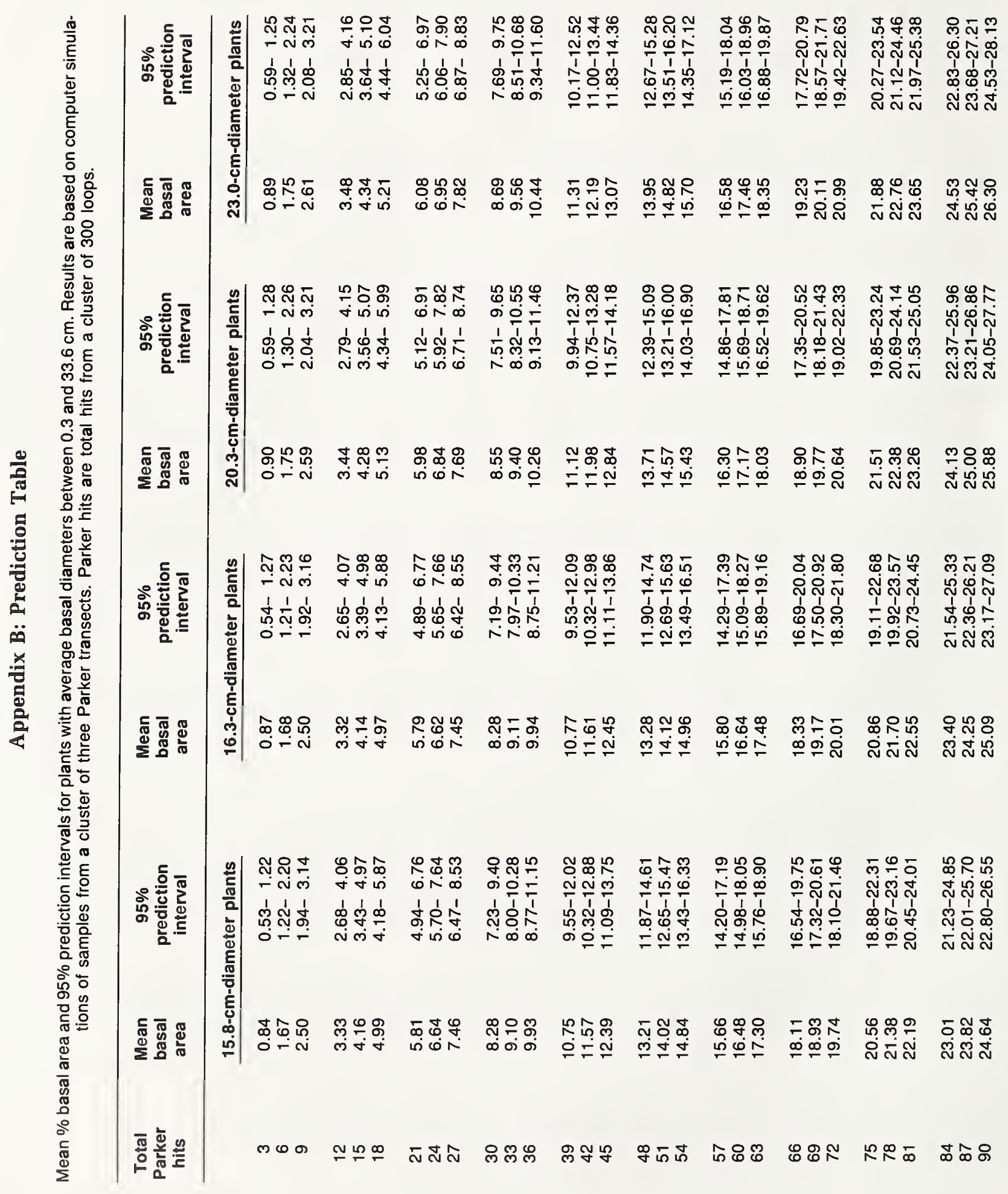




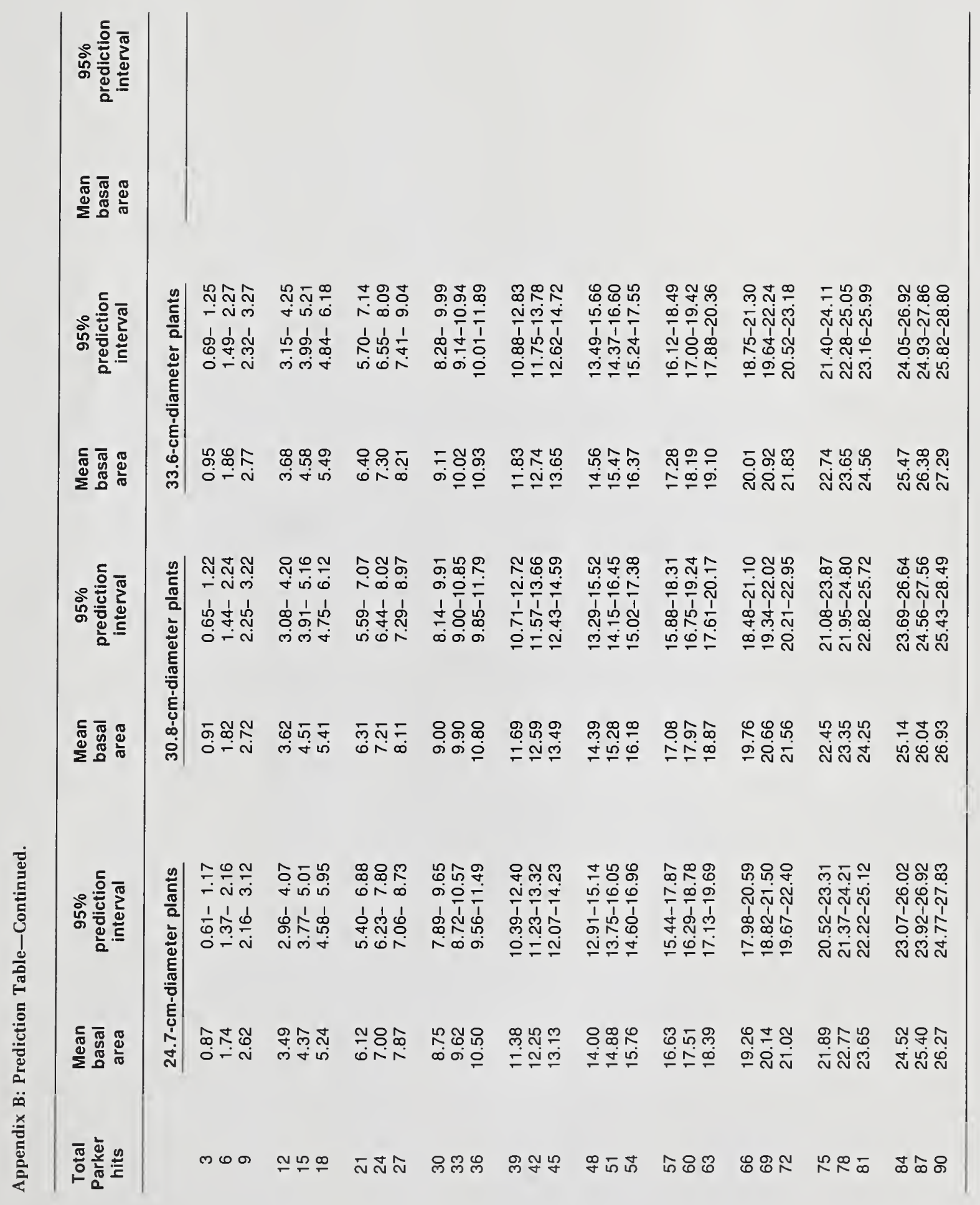





\begin{tabular}{|c|}
\hline $\begin{array}{l}\text { Brady, Ward W.; Cook, John W.; Aldon, Earl F. 1991. A microplot } \\
\text { method for updating loop frequency range trend data: theoretical } \\
\text { considerations and a computer simulation. Res. Pap. RM-295. Fort } \\
\text { Collins, CO: U.S. Department of Agriculture, Forest Service, Rocky } \\
\text { Mountain Forest and Range Experiment Station. } 19 \text { p. }\end{array}$ \\
\hline $\begin{array}{l}\text { Quantitative forms of the relationships between } 3 / 4 \text {-inch loop fre- } \\
\text { quency data (Parker } 3 \text {-step) and data from the Community Structure } \\
\text { Analysis (CSA) sampling method were determined from computer } \\
\text { simulations of grassland vegetation populations. Percent basal area } \\
\text { had a stronger and simpler relationship with Parker frequency than } \\
\text { did CSA canopy cover, CSA density, or CSA frequency. Data from } \\
\text { three or more } 100 \text {-foot transects from homogeneous locations had sig- } \\
\text { nificantly higher precision than data collected from single transects. } \\
\text { A table for converting Parker data to percent basal area is presented } \\
\text { for plants with mean basal diameters between } 0.3 \text { and } 33.6 \mathrm{~cm} \text {. }\end{array}$ \\
\hline
\end{tabular}




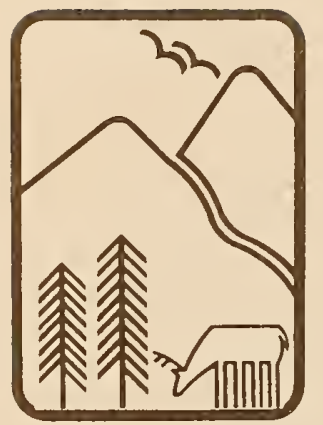

Rocky
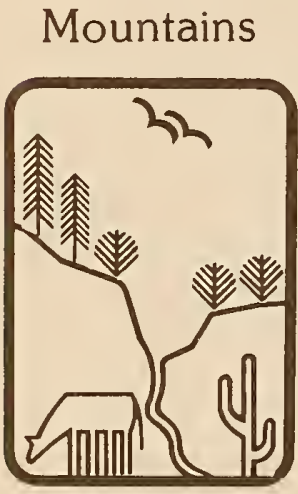

Southwest

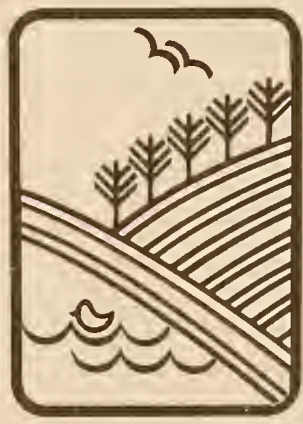

Great Plains
U.S. Department of Agriculture

Forest Service

\section{Rocky Mountain Forest and Range Experiment Station}

The Rocky Mountain Station is one of eight regional experiment stations, plus the Forest Products Laboratory and the Washington Office Staff, that make up the Forest Service research organization.

\section{RESEARCH FOCUS}

Research programs at the Rocky Mountain Station are coordinated with area universities and with other institutions. Many studies are conducted on a cooperative basis to accelerate solutions to problems involving range, water, wildlife and fish habitat, human and community development, timber, recreation, protection, and multiresource evaluation.

\section{RESEARCH LOCATIONS}

Research Work Units of the Rocky Mountain Station are operated in cooperation with universities in the following cities:

Albuquerque, New Mexico

Flagstaff, Arizona

Fort Collins, Colorado*

Laramie, Wyoming

Lincoln, Nebraska

Rapid City South Dakota

Tempe, Arizona

"Station Headquarters: 240 W. Prospect Rd., Fort Collins, CO 80526 